\title{
Electron Spin Resonance Spectra of Polymer Radicals in Aqueous Solution
}

\author{
Roland E. Florin, Fred Sicilio, ${ }^{1}$ and Leo A. Wall \\ Institute for Materials Research, Nationa! Bureau of Standards, Washington, D.C. 20234
}

(June 28, 1967)

\begin{abstract}
Mixing of aqueous polymer solutions containing $\mathrm{Ti}^{3+}$ and $\mathrm{H}_{2} \mathrm{O}_{2}$ in a rapid flow mixer produced radicals by abstraction, $\mathrm{OH}+\mathrm{RH} \rightarrow \mathrm{R} \cdot+\mathrm{H}_{2} \mathrm{O}$, which were observed by electron spin resonance. Oscillation of segments was sufficient to narrow the lines to $0.5-2.0 \mathrm{~g}$. Polymers and radicals identified with more or less, certainty were polyacrylic acid, $m \mathrm{CH}\left(\mathrm{CO}_{2} \mathrm{H}\right) \dot{\mathrm{C}} \mathrm{HCH}\left(\mathrm{CO}_{2} \mathrm{H}\right) m$, polymethacrylic acid, m $\mathrm{C}\left(\mathrm{CH}_{3}\right)\left(\mathrm{CO}_{2} \mathrm{H}\right) \dot{\mathrm{C}} \mathrm{HC}\left(\mathrm{CH}_{3}\right)\left(\mathrm{CO}_{2} \mathrm{H}\right)$ m, polyvinyl alcohol, m $\mathrm{CHOH} \dot{\mathrm{C}} \mathrm{HCHOH} m$, and one indefinite, polyethylene imine, $m \mathrm{CH}_{2} \dot{\mathrm{NCH}} \mathrm{CH}_{2}$ or $m \sim \mathrm{CH}_{2} \mathrm{NOCH}_{2} m$, polyethylene oxide, $\sim \sim \mathrm{CH}_{2} \mathrm{OCHCH}_{2} \mathrm{O} m$. Radicals from polypropylene oxide, dextran, dextrin, soluble starch, and the disaccharide maltose were unidentified; the last three were strikingly similar.

Products of secondary $\mathrm{C}-\mathrm{C}$ scission were not observed with certainty. It is presumed that such reactions are slow compared to the time-scale of the experiment, $10 \mathrm{msec}$. However, some evidence exists for a very rapid $\beta-\mathrm{OH}$ loss in carbohydrate radicals and a slow $\mathrm{C}-\mathrm{O}$ scission in polyethylene: oxide radicals. A large number of related small molecule radicals were investigated, and hyperfine splittings and $g$-values are reported.
\end{abstract}

Key Words: Abstraction, dextran, dextrin, free radicals, hydroxyl, polyacrylic, polyethylene imine, polyethylene oxide, polymer degradation, polymethacrylic acid, polypropylene oxide, polyvinyl alcohol, starch.

\section{Introduction}

Following the initial discovery by Dixon and Norman $[1],{ }^{2}$ electron spin resonance spectra of numerous free radicals have been observed by rapidly mixing solutions of titanous ion, hydrogen peroxide and an appropriate substrate [2-8]. The hydroxyl radicals, identification of which is debatable, react by abstraction [1], addition [7,8] and perhaps electron transfer [3].

$$
\begin{aligned}
\mathrm{Ti}^{3+}+\mathrm{H}_{2} \mathrm{O}_{2} & \rightarrow \mathrm{Ti}^{4+} \dot{\mathrm{O}} \mathrm{H}+\mathrm{OH}^{-} \\
\dot{\mathrm{O}} \mathrm{H}+\mathrm{RH} & \rightarrow \mathrm{R} \cdot \pm \mathrm{H}_{2} \mathrm{O} \\
\dot{\mathrm{O}} \mathrm{H}+\mathrm{CH}_{2}=\mathrm{CH} X & \rightarrow \mathrm{HOCH}_{2} \dot{\mathrm{C}} \mathrm{H} X \\
\dot{\mathrm{O} H}+\mathrm{N}_{2} \mathrm{H}_{4} & \rightarrow \mathrm{N}_{2} \mathrm{H}_{4}^{+}+\mathrm{OH}^{-}
\end{aligned}
$$

With some vinyl monomers, spectra of growing polymer radicals are also observed [8], $\mathrm{HO}\left(\mathrm{CH}_{2} \mathrm{CHX}\right)_{n}$

\footnotetext{
1 Present address: Department of Chemistry, Texas A\&M University, College Station, Tex. 77843 .
}

${ }^{2}$ Figures in brackets indicate the literature references at the end of this paper.
$\mathrm{CH}_{2} \mathrm{CHX} \cdot$, providing a detailed demonstration of the postulated intermediates of the free-radical polymerization mechanism. Similar radicals are also observed in the photolysis of hydrogen peroxide mixed with a substrate [9].

In the present work, we proposed to explore the intermediates and the kinetics pertinent to some kinds of polymer degradation, e.g., the radiolysis of aqueous solutions of dextran [10], by the mixing technique. Water solutions of many polymers mixed with titanous ion and hydrogen peroxide yielded relatively sharp spectra, often permitting identification of polymeric free radicals formed by abstraction. The hope of elucidating quantitative kinetics of the degradation reactions was defeated or at least deferred by doubts regarding the identity of the spectrum attributed to hydroxyl and by the general kinetic complexity of the titanous-peroxide system.

\section{Experimental Procedures}

\subsection{General}

Experimental arrangements have been described earlier [11] and differed little from others in the 
literature $[1,7,8]$. Solutions of titanium trichloride (usually $0.01 M$, with $0.1 M$ sulfuric acid) and hydrogen peroxide (usually $0.1 \mathrm{M}$, no acid), one or both of which contained the substrate $(0.02-2.0 M)^{3}$ were led through a mixer and a flat quartz cell in the cavity of an electron spin resonance apparatus, at flow rates of 1 to $10 \mathrm{~cm}^{3}$ $\sec ^{-1}$.

The composition of solutions was modified in some instances. When acid hydrolysis was feared, e.g., acetals, paraldehyde, some experiments with poly propylene oxide, all the substrate was incorporated in the peroxide solution. Concentrations where reported refer to the overall solution after mixing.

In some studies at elevated temperatures, 40 to $50{ }^{\circ} \mathrm{C}$, or at lowest substrate concentrations, the peroxide concentration was reduced to one-half or one-fourth the usual. Without this expedient, the overall reaction velocity at these temperatures was in general so high that only small concentrations of radicals remained at feasible flow rates.

With amine substrates, radical spectra were obtained occasionally by selective throttling of flow from the two streams, but more reliably by partially neutralizing the amine to a $p \mathrm{H}$ of 7.5 to 8.5 before use, with carbon dioxide added as dry ice or bubbled from a cylinder. In some experiments with ethylene glycol and polyethylene oxide, high $p \mathrm{H}$ of 5 to 8 was obtained either by adding concentrated buffers of borax and sulfuric acid, or by omitting sulfuric acid from the titanium solution and adding carbonate and bicarbonate to the peroxide. At higher $p \mathrm{H}$ and also with certain gelforming polymers, e.g., polyvinyl alcohol, the mixer tended to become clogged with precipitate or gel, especially at low flow rates. Precipitates were removable by rapid flushing with water, hydrochloric acid and acidified peroxide, provided the clogging was not severe. Polyvinyl alcohol gels were removable only by dismantling the apparatus and lifting out the plug of gel with a fine hooked wire.

\subsection{Materials}

Reagents have been described [11]. As smallmolecule substrates, chemically pure and pure grades of fresh commercial materials were used. The less pure materials are believed to have had an assay of 95 to 99 percent ordinarily. At this level of purity, contaminants are judged to be unimportant, except for the possible occurrence of very unreactive substrates containing an effective inhibitor in high concentration. Different grades showed little difference in behavior. Further comments are needed on the polymers.

Polyvinyl alcohol was the 98 percent hydrolyzed material, in several molecular weight grades. In most experiments the lowest molecular weight was used, viscosity 4 to $6 \mathrm{cp}$ in 4 percent solution, because of the convenience of low solution viscosity. Polyacrylic acid was a commercial solution, from the Borden Co., light brown in color. Polymethacrylic acid was a clear solution of low molecular weight, less than 5000 , from

\footnotetext{
${ }^{3}$ For a polymer substrate, $M$ is base molar.
}

Rohm and Haas. Polyethylene imine was a clear, viscous 50 percent solution from the Borden Co. Polyethylene oxide was either the liquid "polyethylene glycol 400" or the solid "polyethylene glycol 20,000," which showed minor differences of behavior.

Dextran was either "Macrodex" (Pharmacia, Stockholm) or the product of Pharmachem Corporation. The two products did not differ appreciably in behavior, although in general dextrans are reported to show wide variation in percentage of 1,6-linkages.

Dextrin was commercial corn dextrin, and soluble starch the usual analytical-grade product. Amylose was "Nepol," commercial grade, A. E. Staley Mfg. Co.

\subsection{Measurement of $g$-Values and Splittings}

Hyperfine splittings and $g$-values were determined with ultimate reference to Frémy's salt potassium nitrosodisulfonate, assuming $g=2.00550 \pm 0.00005$. $a=13.1 \pm 0.1 \mathrm{G}[12,13]$.

It was not possible to obtain spectra of the radicals and the nitrosodisulfonate ion simultaneously in the same solution, as was done earlier with hydroxyl [1]. Four alternative methods were used: (1) After a recognizable portion of the spectrum had been obtained in the usual way, enough Frémy's salt to give a faint pink color $(0.1-0.5 \mathrm{~g} / \mathrm{l})$ was added to the peroxide solution, and the titanium solution was shut off, without interrupting the scan. As a modification, a solution of Frémy's salt was sometimes substituted for the peroxide solution. The resultant spectrum contained initial lines of the radical spectrum, and some or all lines of the nitrosodisulfonate spectrum. Relative positions of all lines were estimated by comparing the ordinary spectrum with the composite. This procedure was used with most spectra. (2) The spectrum was taken in the usual way, but a small capillary, of $0.1-0.5 \mathrm{~mm}$ diam, of quartz or polytetrafluoroethylene insulation tubing was filled with Frémy's salt solution, plugged with wax, and either taped to the flat cell or inserted to rest against it. The spectrum contained all lines of both spectra, superposed. (3) A small proportion of methanol or ethanol, 5 to 20 percent of the total amount, and chosen by trial, was added to the substrate investigated. The methanol and ethanol spectra were measured independently against Frémy's salt. The spectrum contained all lines of the principal and reference spectrum, the former considerably reduced in intensity. (4) When the "hydroxyl" spectrum was present, the distance from it to the center of the principal spectrum was measured.

These methods cannot approach the accuracy of simultaneous measurement of microwave and proton probe frequencies [9]. The principal sources of error to consider are nonlinearity and limited reproducibility of magnetic field scanning rate, and frequency shifts upon changing solutions. In the $26 \mathrm{G}$ region covered by Frémy's salt, the upper $13 \mathrm{G}$ interval varied from less than 0.4 percent to more than 2 percent shorter than the lower interval on the recorder chart. Discrepancies among like intervals were greater in the 
more extended spectrum of $\mathrm{CH}_{3} \dot{\mathrm{C}} \mathrm{HOH}$ from ethanol, and attempts to find a consistent quadratic correction formula were unsuccessful.

In successive scans of a given interval, discrepancies of 1 or 2 percent were typical, after stabilization by several hours of use.

The microwave frequency shift on changing from pure water to titanium and peroxide was undetectable by a resonant cavity meter, therefore, less than $0.7 \mathrm{MHz}$, which involves $0.2 \mathrm{G}$ or 0.0001 units in a $g$-value.

Method 3 can give negligible errors, less than $0.2 \mathrm{G}$ or $0.0001 g$-units, provided the spectrum investigated has well-identified lines lying close to the lines of $\mathrm{CH}_{3} \dot{\mathrm{C}} \mathrm{HOH}$. With complex spectra it suffers from an increased chance of overlap of lines and of gross mistakes in identification of lines. In method 2 the error due to differences of field between sample and reference can be made negligible with usual magnetic field homogeneity. The $g$-value can be established within an uncertainty of \pm 0.00003 or so, if the sample radical contains reliable lines within $5 \mathrm{G}$ of center; otherwise nonlinearity introduces greater errors. Likewise splitting parameters can be established within $0.2 \mathrm{G}$ if based on measurements in the region of the reference spectrum. Method 1, depending on a reproducibility of 1 to 2 percent over a region often $50 \mathrm{G}$ in extent, can easily lead to errors of $1 \mathrm{G}, \pm 0.0006$ units in $g$, and is scarcely adequate to make the desired distinctions. Its results can be regarded as best values with a large uncertainty. Method 4 is of use only in the absence of other data. If two or more spectra are present, the differences of $g$-value and ratios of splittings are often much more closely known than the absolute values.

In the detailed discussions that follow, line positions are taken as the crossover point of the second derivative curve and line widths are those between derivative maxima. (Indicated error limits are estimated uncertainties.) Hyperfine splittings are considered accurate to 1 or 2 percent unless based upon measurements of lines which are either broad, overlapped, or remote from a reference spectrum. Uncertainties in $g$-value are assigned on the basis of either repeated scan interval uncertainty $(2 \%)$ and distance between trusted lines of reference and sample spectra, Methods 1 and 4, or of such distances and a nonlinearity allowance estimated from symmetrical intervals in the spectrum, Methods 2 and 3, or of scaling uncertainties when other errors are negligible. The $g$-values quoted are uncorrected for second-order shift [16] except in comparisons where this is indicated.

\section{Results and Discussion}

\subsection{Arrangement, Nomenclature, General Observations, and Kinetics}

Results are arranged according to chemical type, each polymer being discussed along with the small molecules necessary for characterization. From the line widths, it is obvious that, as in NMR of polymer solutions [14], the segmental motion is nearly as efficient as the tumbling motion of small molecules in narrowing line widths. Kinetic considerations will be dealt with elsewhere. By way of summary, it should be noted that the identity of the lines previously taken as hydroxyl [2] is incertain [15a]. At least one of the lines seems to be that of a radical complexed with titanium [11]. With decreasing flow rate, i.e., increasing time, the radical spectra disappear much more rapidly than the supposed hydroxyl spectra [15b] in a time comparable to that for the appearance of the yellow color of peroxide-complexed $\mathrm{Ti}^{4+}$; it is thus plausible that the radicals exist in a quasi steady-state concentration dependent largely upon the consumption of $\mathrm{Ti}^{3+}$ and generation of $\mathrm{OH}$. When both an organic radical and the supposed hydroxyl spectra are present, the hydroxyl concentration can increase with time while the organic radical concentration is decreasing; this suggests, without proving, that the "hydroxyl" is not a predecessor of the organic radical but some sort of secondary product with a very low termination rate. The $\mathrm{HO}_{2}$ radical could satisfy this requirement.

Where scissions and cross-links have been measured, they are much less than the $\mathrm{Ti}^{3+}$ consumed, which on the steady-state hypothesis has some relation to radical terminations; therefore, most of the radicals seen do not result in immediate cross-links or scissions.

Finally, many of the spectra show decreased line intensity at low field. The decrease is primarily associated with field, independent of direction of scan and recurring in repetitions. It is not much altered by lowering microwave power from $10 \mathrm{mw}$ to $1 \mathrm{mw}$ and persists even in envelope spectra taken at high field modulation.

Similar trends are seen elsewhere $[2,8]$ even in metal-free photolytic systems [27] and attributed by Fischer [8] to cross terms between the dipolar anisotropic hyperfine interaction and the anisotropic $g$-tensor [15c]. The magnitude of the peak height differences ranged from less than 10 percent in $\mathrm{CH}_{2} \mathrm{OH}$ to 30 percent in paraldehyde. The direction of the effect, less intensity at low field, was always the same: for equivalent $\alpha$ protons, $\dot{\mathrm{C}} \mathrm{H}_{2} \mathrm{OH}$, for equivalent $\beta$ protons, $\mathrm{CH}_{3} \dot{\mathrm{C}}(\mathrm{OR})_{2}$ and Dixon and Norman's $\left(\mathrm{CH}_{3}\right)_{2} \dot{\mathrm{COH}}$ [2], and for composites of both.

This is opposite to the variation usually seen with N splittings [15d], but like that for semiquinone protons [15e]. If the cause is correctly assigned, it appears that the anisotropic hyperfine $g$-tensor term has the same sign for $\alpha$ and $\beta$ protons, although the isotropic hyperfine coefficients are of opposite sign [15f, g]. There was no definite example of the alternating line widths predicted in more comprehensive treatments of the effect [15h]. We considered also a possible fielddependent lowering of cavity $Q$ by a radical, e.g., $\mathrm{OH}$ or some metallic complex, having high concentration and an undetectably broad ESR absorption spectrum. This explanation is unlikely if the undetected species 
is hydroxyl, for the radicals from acetic acid show little or no intensity anomaly, although because of the low reactivity many hydroxyl radicals should be present.

There are several conflicting conventions for identification of hyperfine splittings $[2,8,9,17]$. Where possible we follow the older notation exemplified in the formula,

$$
\begin{aligned}
& \mathrm{CH}_{3} \dot{\mathrm{C}} \mathrm{HOCH}_{3} \\
& \beta \quad \alpha \quad \beta \gamma
\end{aligned}
$$

where $a_{\alpha}$ denotes protons at the site of the unpaired electron, $a_{\beta}$, at the next position, $a_{\gamma}$ at the third. Protons in the $\gamma$ position across an oxygen linkage are distinguished by $a_{\gamma_{0}}$. Positions adjoining a position of appreciable spin density, e.g., the mid position of an allyl radical, can be spoken of as $\beta$ to this position. In more complicated cases, subscripts or superscripts identify either the group or the position in a numbered structural formula. In stable molecules $\alpha$ and $\beta$ use the functional group as the point of reference.

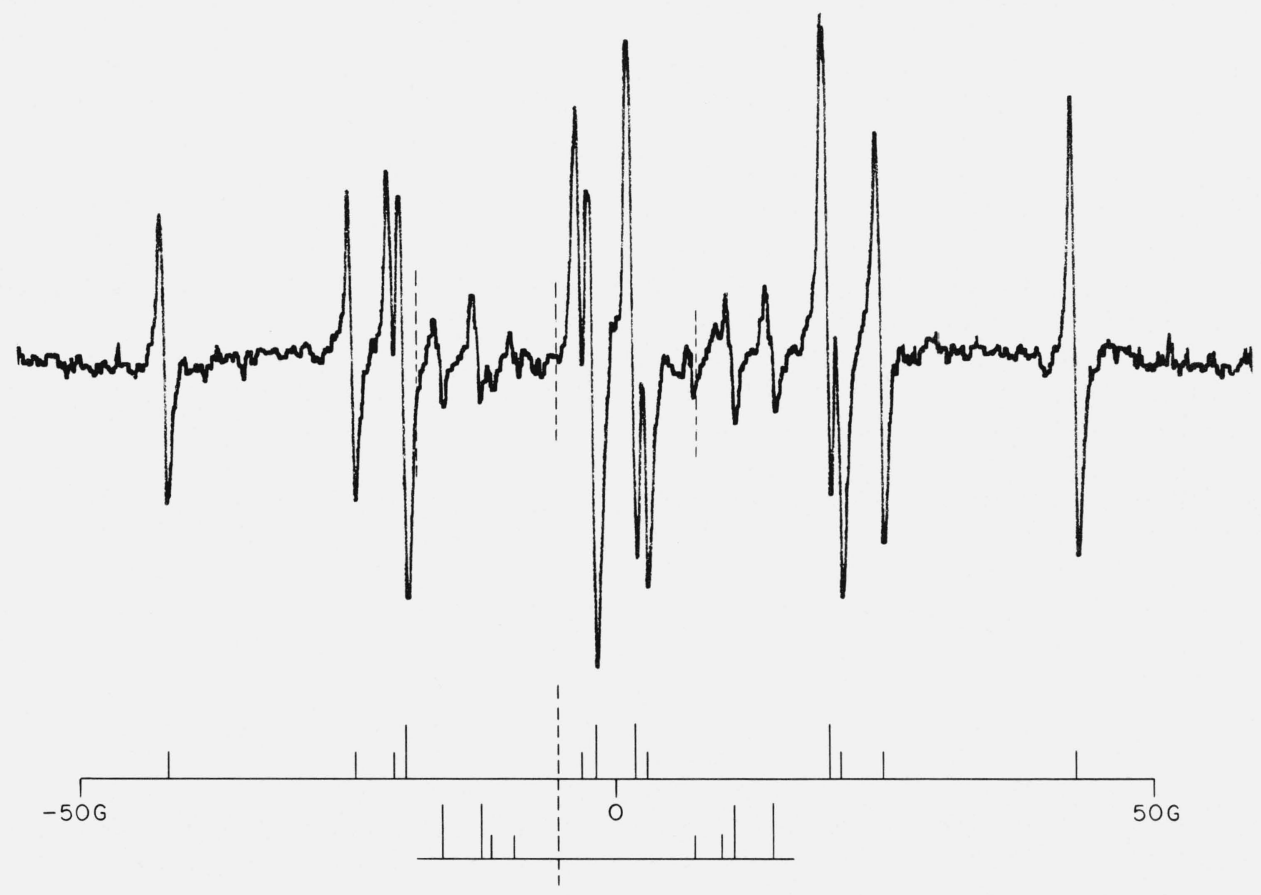

FigURE 1. ESR spectrum from 2-buten-1,4-diol, $0.1 \mathrm{M}, 27^{\circ} \mathrm{C}, 6.7 \mathrm{~cm}^{3} / \mathrm{sec}$.

Line schemes: upper, $\mathrm{CH}_{2} \mathrm{OHCHOHCHCH} \mathrm{HH}_{2} \mathrm{OH}$; lower, extra lines, possibly from $\mathrm{CH}_{2} \mathrm{OHCH}=\mathrm{CHCHOH} . .$. , line positions of $\mathrm{NO}\left(\mathrm{SO}_{3}\right)_{\overline{2}}^{-}$ 


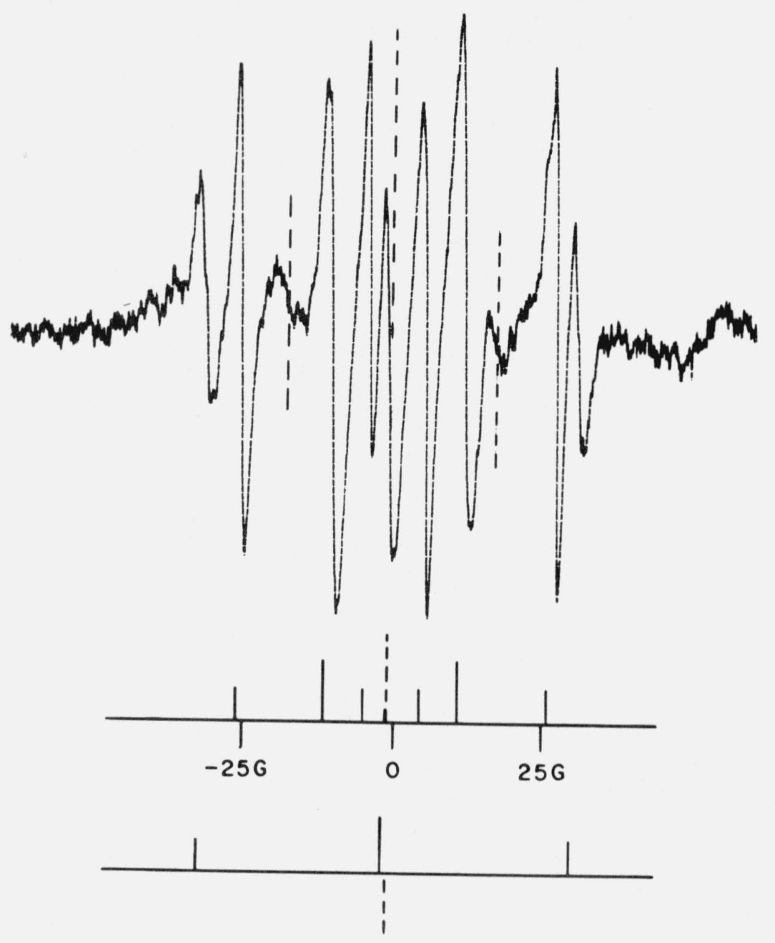

FIGURE 2. ESR spectrum from polyvinyl alcohol, $0.25 \mathrm{M}, 24{ }^{\circ} \mathrm{C}$, $6.9 \mathrm{~cm}^{3} / \mathrm{sec}$.

Hydrogen peroxide $0.0125 \mathrm{M}$. Line schemes: upper, attributed to m $\mathrm{CHOHCHCHOH}$ m' lower, uncertain extra lines. ...., line positions (centers of poorly resolved pairs) of $\mathrm{CH}_{2} \mathrm{OH}$ by mixture method.

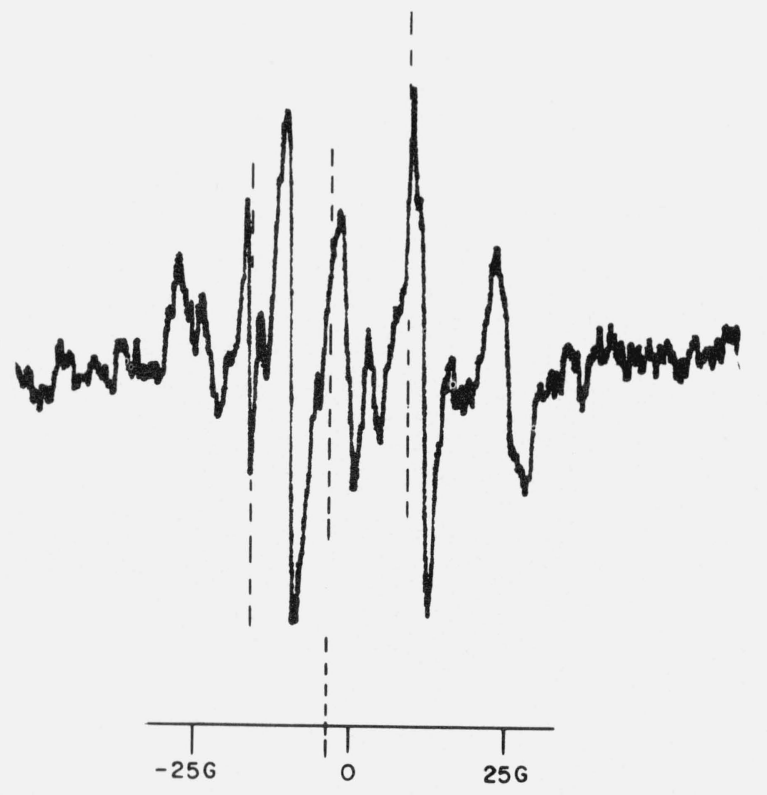

FigURE 3. ESR spectrum from polyacrylic acid, $0.23 \mathrm{M}, 27^{\circ} \mathrm{C}$, $9.8 \mathrm{~cm}^{3} / \mathrm{sec}$.

$\cdots$, line positions of $\mathrm{NO}\left(\mathrm{SO}_{3}\right)_{2}$.

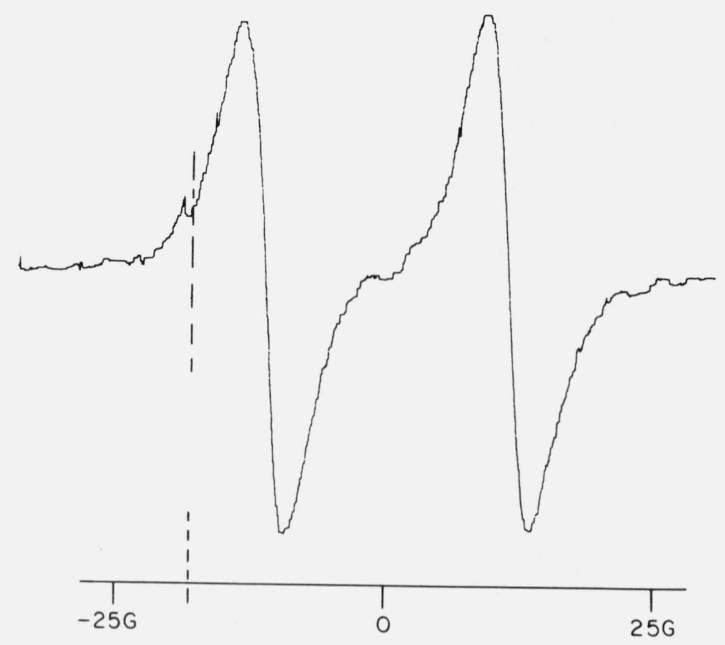

FIGURE 4. ESR spectrum from polymethacrylic acid $0.5 \mathrm{M}, 41{ }^{\circ} \mathrm{C}$, $5.7 \mathrm{~cm}^{3} / \mathrm{sec}$. $\ldots$, line position of $\mathrm{OH}$ or $\mathrm{HO}_{2}$ at $\mathrm{g}=1.0128$.

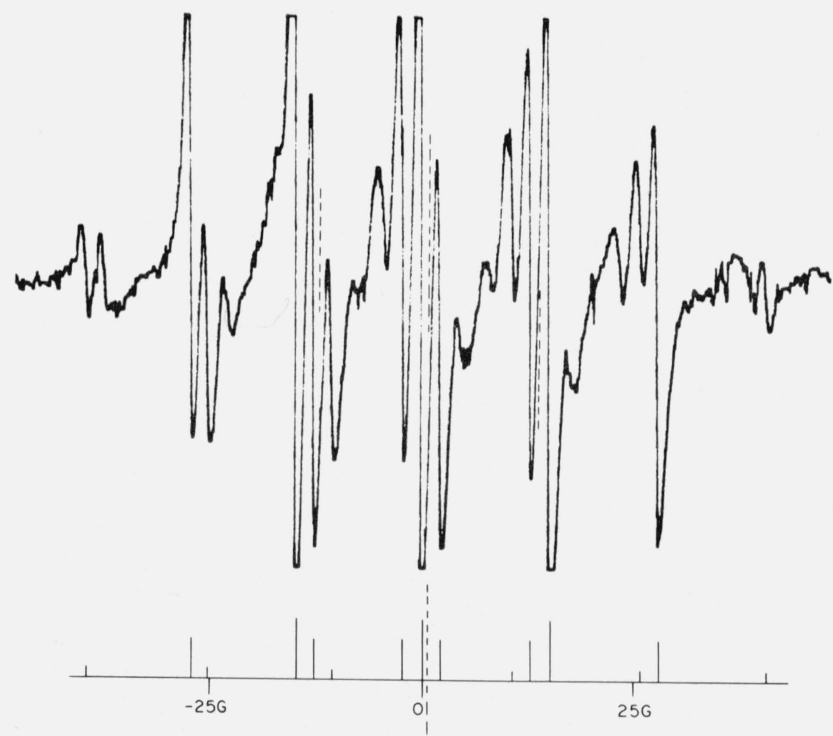

FigURE 5. ESR spectrum from polyethylene imine, $0.25 \mathrm{M}, 30^{\circ} \mathrm{C}$, $7.0 \mathrm{~cm}^{3} / \mathrm{sec}$

Mixing ratio of $\mathrm{TiCl}_{3}$ and polymer $-\mathrm{H}_{2} \mathrm{O}_{2}$ solutions adjusted to pale yellow effluent color. Line scheme $m \mathrm{CH}_{2} \mathrm{NOCH}_{2}$ m or $m \mathrm{CH}_{2} \mathrm{NCH}_{2} m \ldots$, line positions of $\mathrm{NO}\left(\mathrm{SO}_{3}\right)^{\prime}=$ 


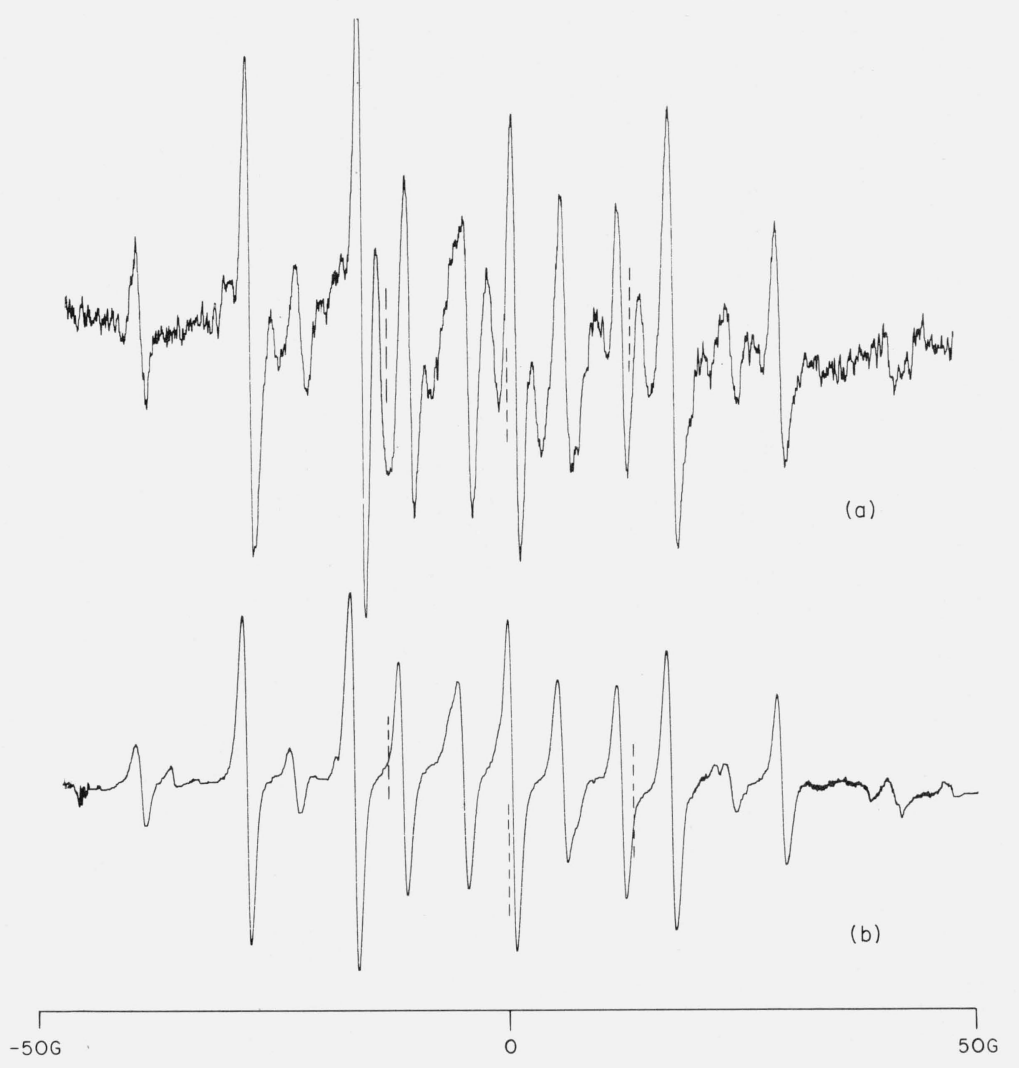

FIGURE 6. ESR spectra from diethylamine.

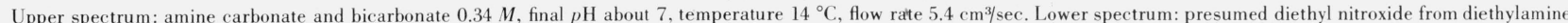
carbonate $0.55 \mathrm{M}, \mathrm{H}_{2} \mathrm{O}_{2} 0.035 \mathrm{M}$, ceric ammonium sulfate $0.024 \mathrm{M}$, final $p \mathrm{H} 8$ or 8.5 . Temperature $25^{\circ} \mathrm{C}$, flow rate $5.3 \mathrm{~cm}^{3} / \mathrm{sec}, \cdots$, line positions of $\left.\mathrm{NO}(\mathrm{SO})_{2}\right)_{2}$.

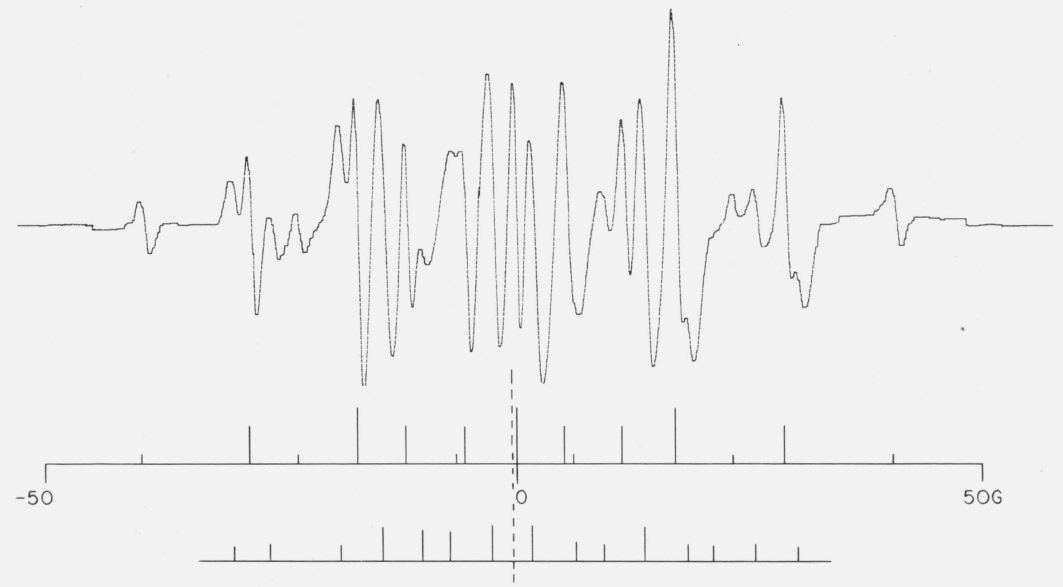

FIGURE 7. ESR spectrum from diethylamine.

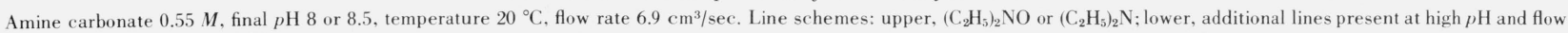
rate. .... line positions of $\mathrm{NO}\left(\mathrm{SO}_{3}\right)_{2}$, 


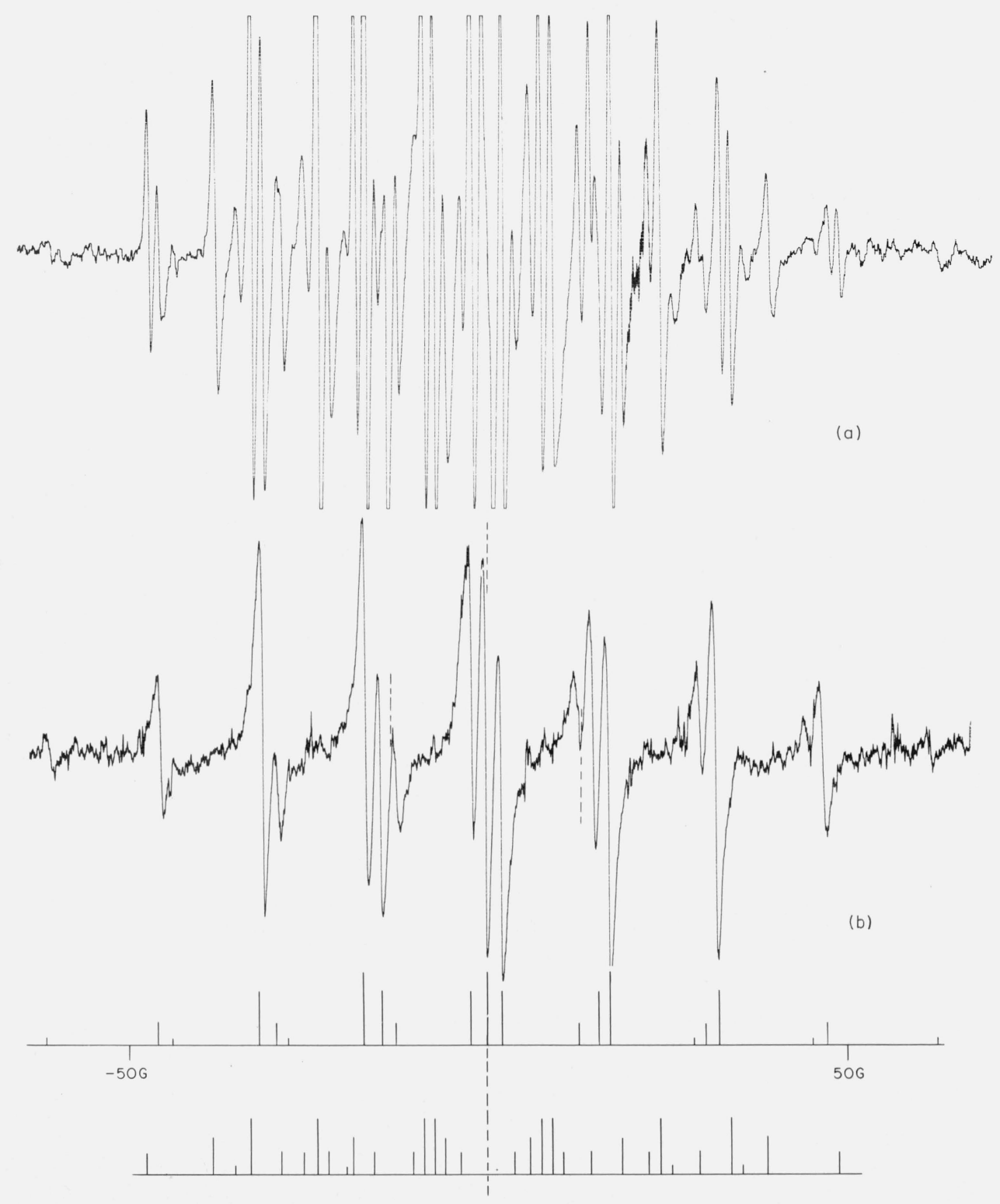

FigURE 8. ESR spectra from dimethylamine.

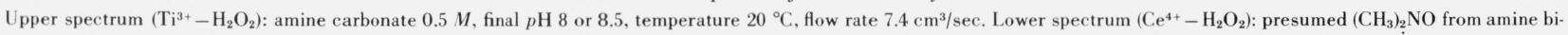

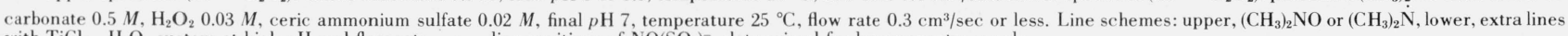
with $\mathrm{TiCl}_{3}-\mathrm{H}_{2} \mathrm{O}_{2}$ system at high $p \mathrm{H}$ and flow rate. .... line positions of $\mathrm{NO}\left(\mathrm{SO}_{3}\right)_{2}^{=}$, determined for lower spectrum only.

55 


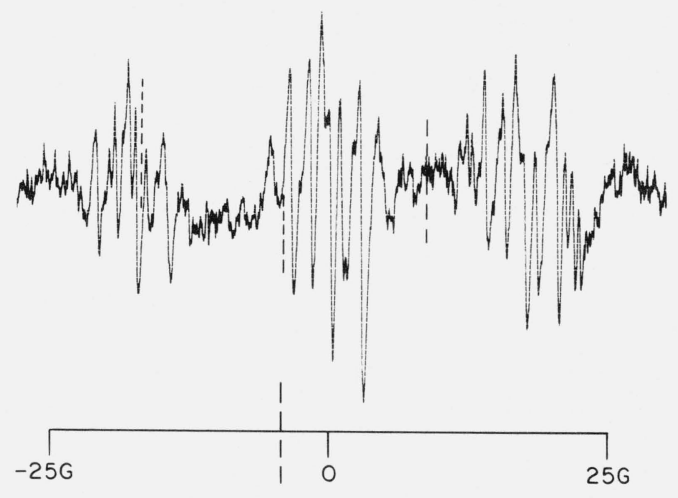

FIGURE 9. ESR spectrum from $N, N$-dimethylformamide, $0.9 \mathrm{M}$ $27{ }^{\circ} \mathrm{C}, 7.3 \mathrm{~cm}^{3} / \mathrm{sec}$.

.... line positions of $\mathrm{NO}\left(\mathrm{SO}_{3}\right)_{2}$.

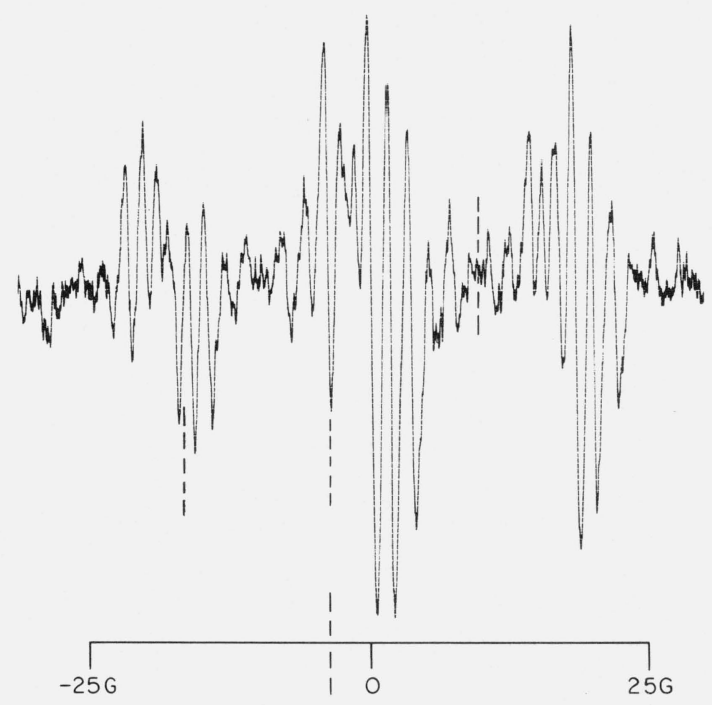

FigURE 10. ESR spectrum from N,N-dimethylacetamide, $0.15 \mathrm{M}$, $27{ }^{\circ} \mathrm{C}, 6.0 \mathrm{~cm}^{3} / \mathrm{sec}$ .... line positions of $\mathrm{NO}\left(\mathrm{SO}_{3}\right)_{2}$,

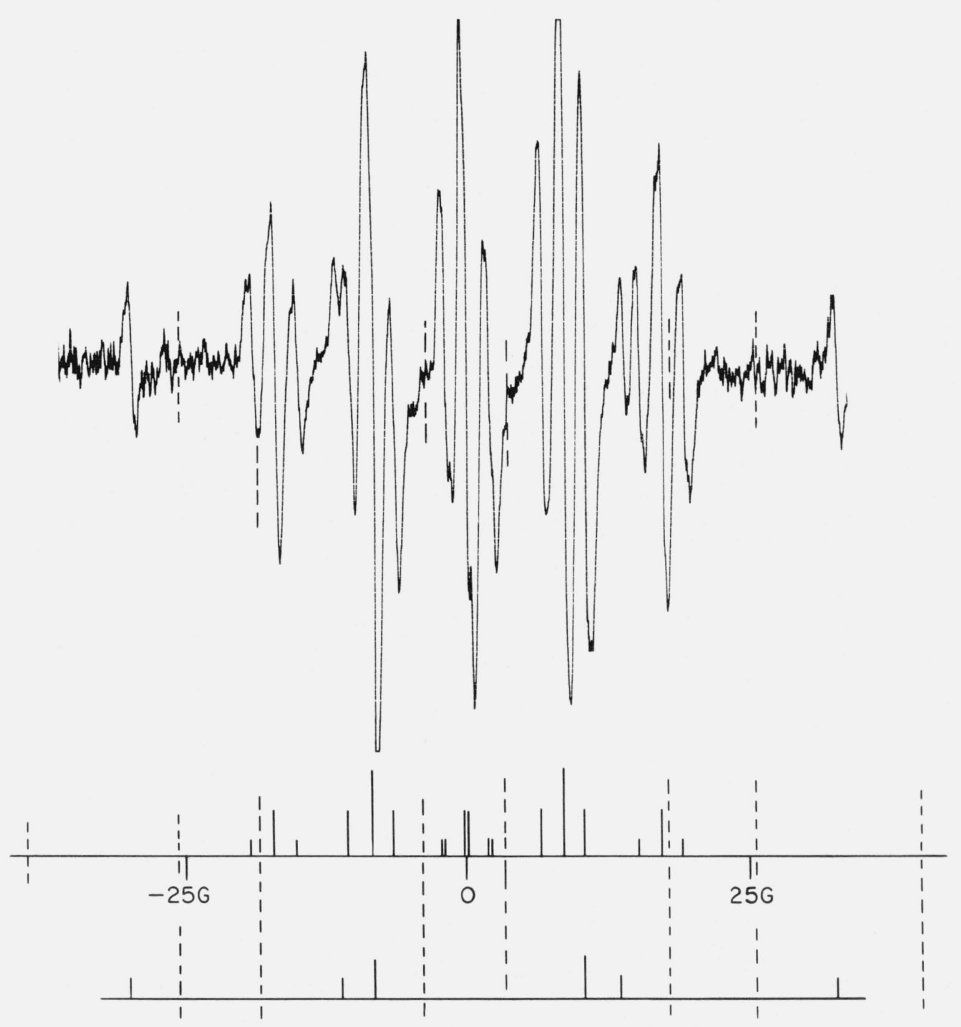

FIGURE 11. ESR spectrum from polyethylene oxide, mol. wt. $400,0.5 \mathrm{M}, 25^{\circ} \mathrm{C}, 5.3 \mathrm{~cm}^{3} / \mathrm{sec}$.

Line schemes: upper m $\mathrm{CH}_{2} \mathrm{OCHCH}{ }_{2} \mathrm{O}$, lower, attributed to $\mathrm{HOCHCH}_{2} \mathrm{O}_{m} \ldots$. . . line positions of $\mathrm{CH}_{3} \mathrm{CHOH}$ reference spectrum, by mixture experiments. 


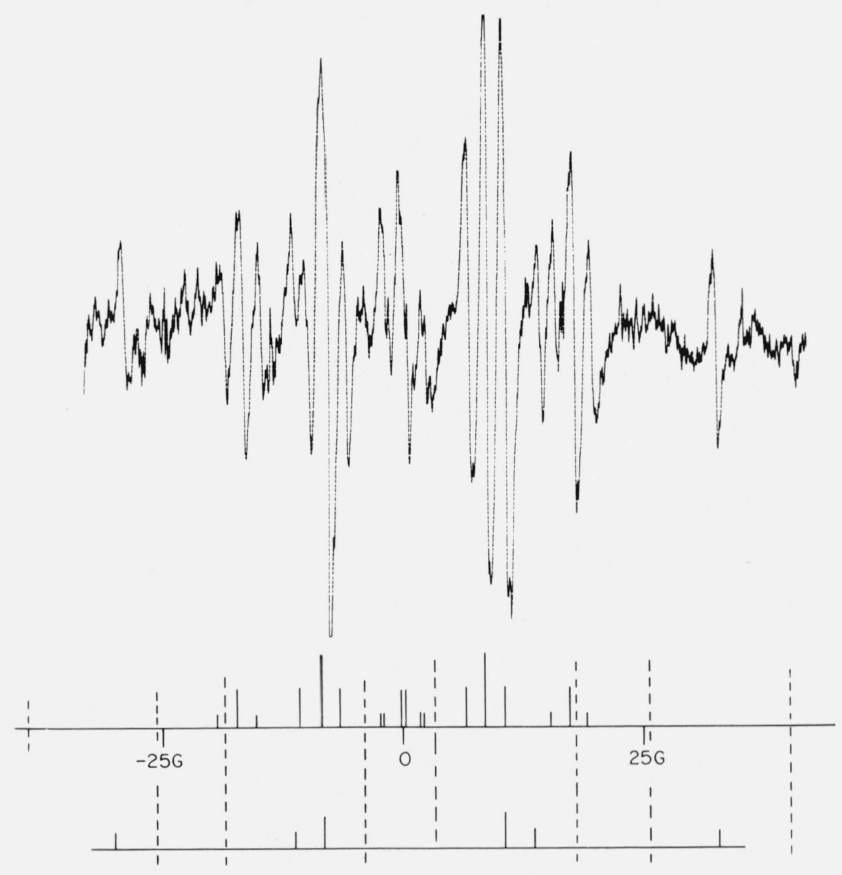

FIGURE 12. ESR spectrum from polyethylene oxide, mol. wt. 400, $0.5 \mathrm{M}, 41^{\circ} \mathrm{C}, 5.3 \mathrm{~cm}^{3} / \mathrm{sec}$.

$\mathrm{H}_{2} \mathrm{O}_{2}$ concentration $0.018 \mathrm{M}$ in place of usual $0.05 \mathrm{M}$. Line schemes as in figure $11 \ldots$, line positions of $\mathrm{CH}_{3} \mathrm{CHOH}$, from figure 11 .
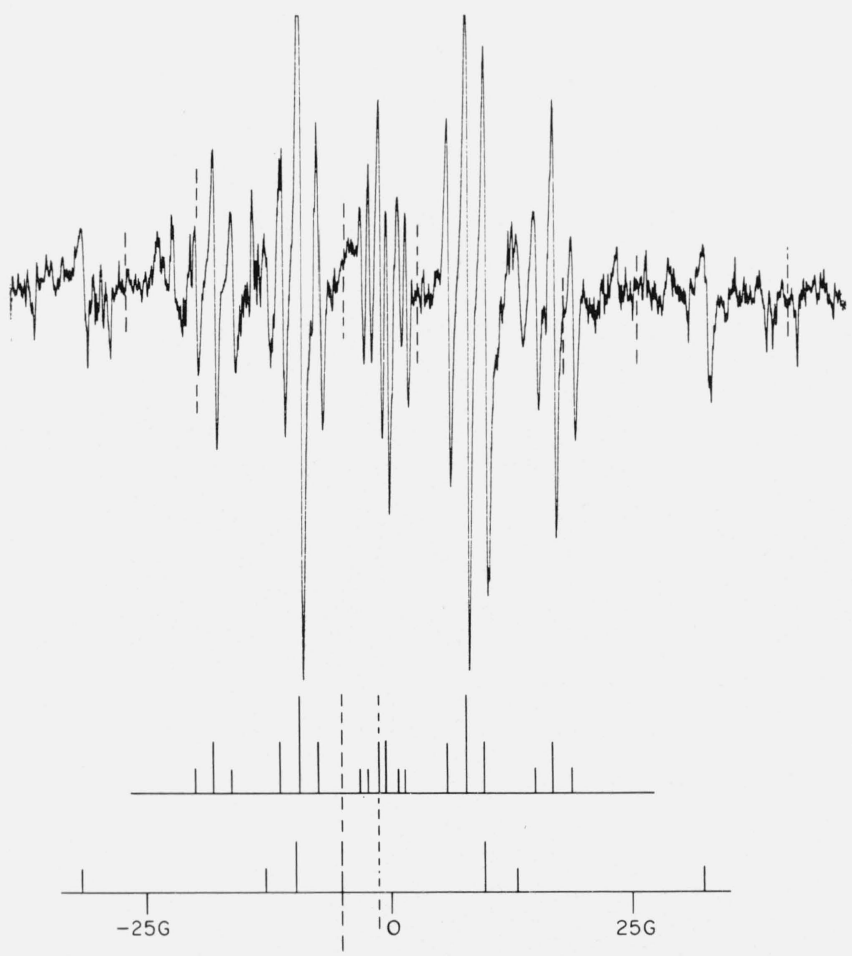

FIGURE 13. ESR spectrum from diethylene glycol $0.18 \mathrm{M}, 22{ }^{\circ} \mathrm{C}$, $7.1 \mathrm{~cm}^{3} / \mathrm{sec}$.

Line schemes: upper $\mathrm{HOCH}_{2} \mathrm{CHOCH} \mathrm{CH}_{2} \mathrm{OH}$, lower, probably $\mathrm{HOCHCH}_{2} \mathrm{OCH}_{2} \mathrm{CH}_{2} \mathrm{OH}$ .... line positions of $\mathrm{CH}_{3} \mathrm{CHOH}$ by mixture method (in spectrum), or centers of $\mathrm{CH}_{3} \mathrm{CHOH}_{2}$ and $\mathrm{NO}\left(\mathrm{SO}_{3}\right)_{2}=$ spectra (in line schemes).

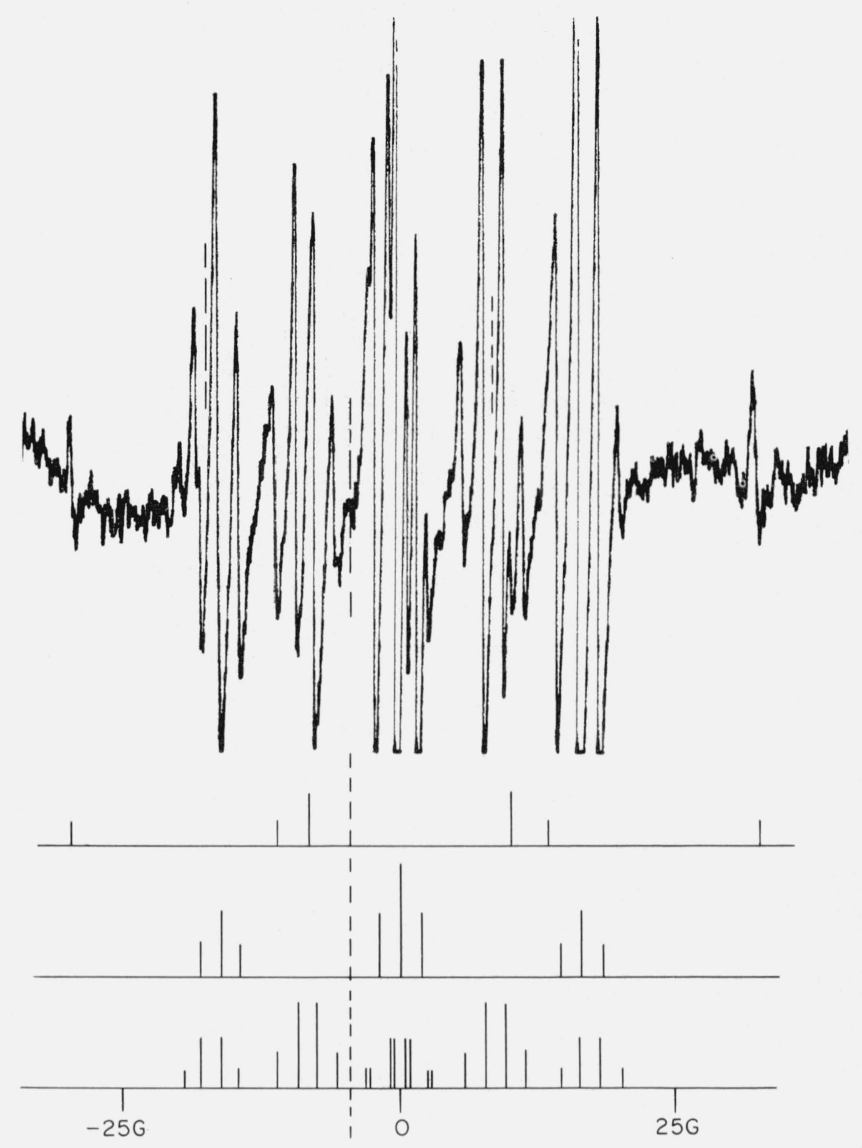

FIGURE 14. ESR spectrum from 1,2-dimethoxyethane $0.1 \mathrm{M}$, $27^{\circ} \mathrm{C}, 6.3 \mathrm{~cm}^{3} / \mathrm{sec}$.

Line schemes: upper, attributed to $\mathrm{HOC}^{\mathrm{C}} \mathrm{HCH}_{2} \mathrm{OCH}_{3}$, middle, $\mathrm{C} \mathrm{H}_{2} \mathrm{OCH}_{2} \mathrm{CH}_{2} \mathrm{OCH}_{3}$, lower, $\mathrm{CH}_{3} \mathrm{OC} \mathrm{HCH}_{2} \mathrm{OCH}_{3}, \cdots$, line positions of $\mathrm{NO}\left(\mathrm{SO}_{3}\right)_{2}$.

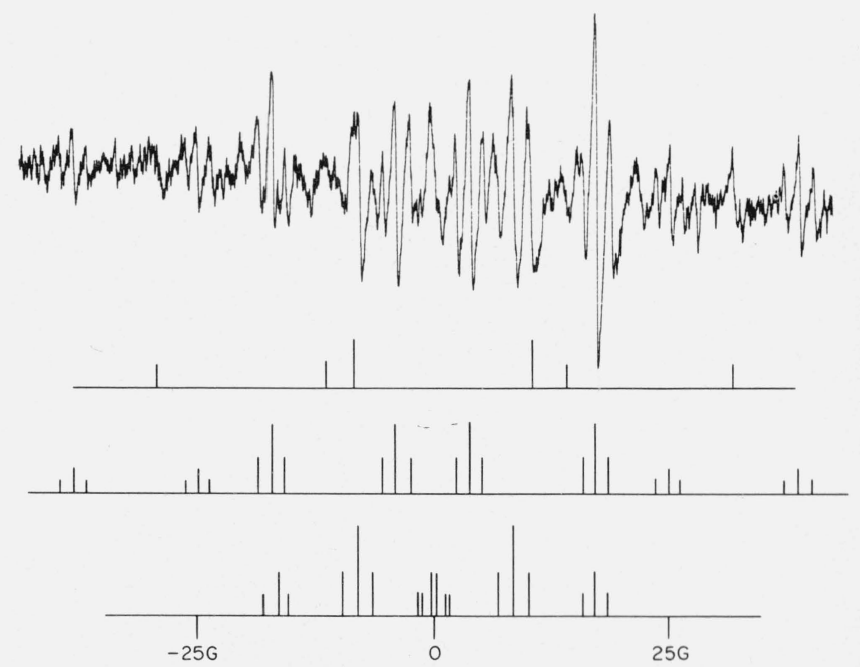

FIGURE 15. ESR spectrum from bis-2-ethoxyethyl ether, $0.38 \mathrm{M}$, $27^{\circ} \mathrm{C}, 7.6 \mathrm{~cm}^{3} / \mathrm{sec}$.

Line schemes (provisional in view of severe overlap): upper, attributed to $\mathrm{HOCHCH}_{2} \mathrm{O}$ middle $\mathrm{CH}_{3} \dot{\mathrm{C}} \mathrm{HOCH}_{2} \mathrm{CH}_{2} \mathrm{Om}$, lower $\mathrm{CH}_{3} \mathrm{CH}_{2} \mathrm{OCHCH} \mathrm{O}_{m}$ and $m \mathrm{OCH}_{2} \mathrm{CHOCH}_{2} m$ 


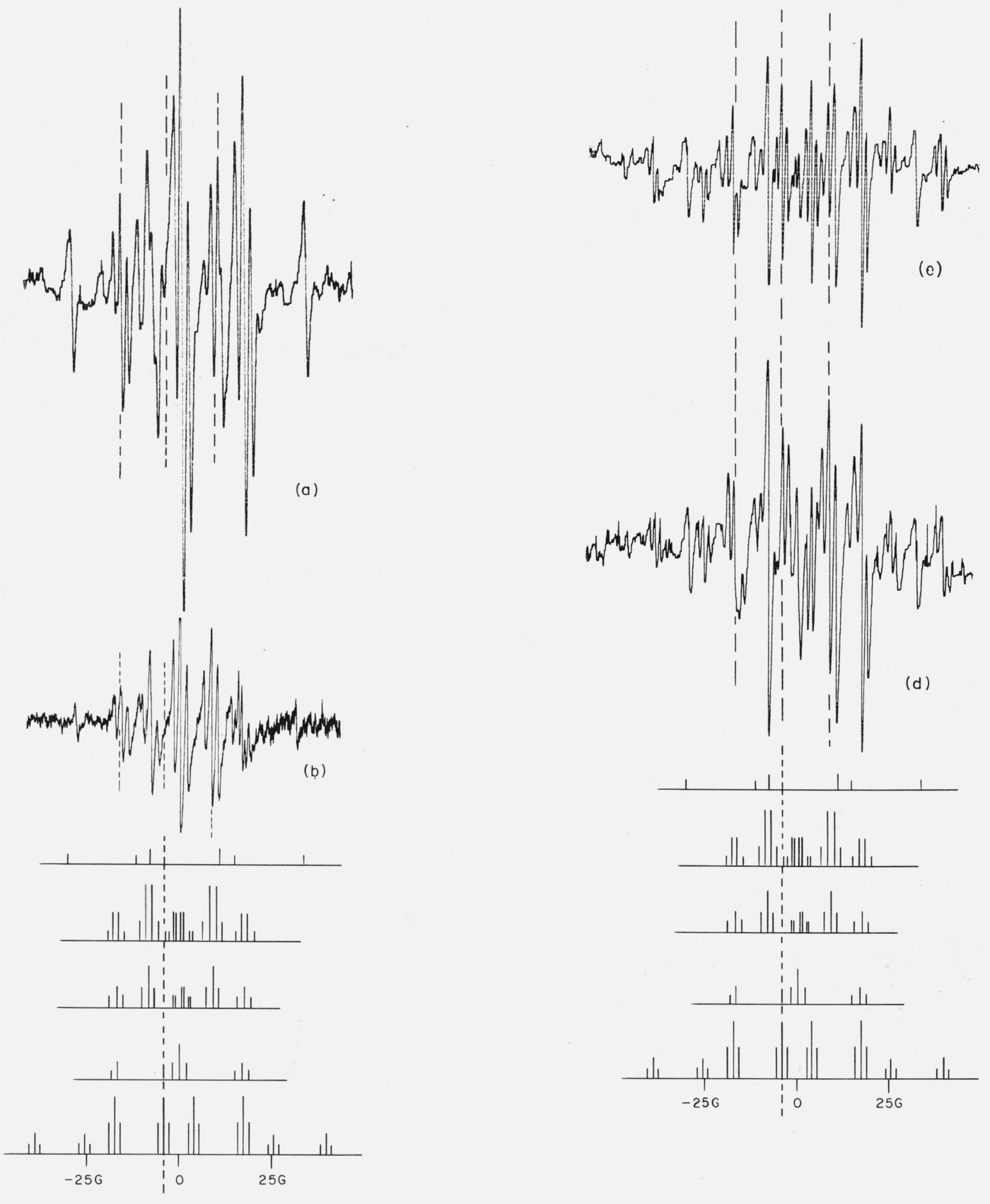

FigURE 16. ESR spectra of miscellaneous ethylene glycol ethers, $0.25 \mathrm{M}, 27-29{ }^{\circ} \mathrm{C}, 5-10 \mathrm{~cm}^{3} / \mathrm{sec}$.

(a) $\mathrm{CH}_{3} \mathrm{OCH}_{2} \mathrm{CH}_{2} \mathrm{OH}$

(b) $\mathrm{CH}_{3}\left(\mathrm{OCH}_{2} \mathrm{CH}_{2}\right)_{4} \mathrm{OCH}$

(b) $\mathrm{CH}_{3}\left(\mathrm{OCH}_{2} \mathrm{CH}_{2}\right)_{4} \mathrm{OCH}$

(c) $\mathrm{C}_{2} \mathrm{H}_{5} \mathrm{OCH}_{2} \mathrm{CH}_{2} \mathrm{OH}$,

(d) $\mathrm{C}_{2} \mathrm{H}_{5}\left(\mathrm{OCH}_{2} \mathrm{CH}_{2}\right)_{2} \mathrm{OH}$,

(f) $\mathrm{C}_{4} \mathrm{H}_{9}\left(\mathrm{OCH}_{2} \mathrm{CH}_{2}\right)_{2} \mathrm{OH}$.

Line schemes: upper, $\mathrm{HOC} \mathrm{HCH}_{2} \mathrm{Om}, 2 \mathrm{~d} \mathrm{CH}_{3} \mathrm{OCHCH}_{2} \mathrm{O}, 3 \mathrm{~d} \mathrm{CH}_{3} \mathrm{CH}_{2} \mathrm{OCHCH}_{2} \mathrm{O}$ m and

m $\mathrm{CH}_{2} \mathrm{OCHCH}_{2} \mathrm{Om}$, 4th $\mathrm{CH}_{2} \mathrm{OCH}_{2}$ m, 5th $\mathrm{CH}_{3} \mathrm{CHOCH}_{2} \mathrm{~m} / \cdots$, line positions of 

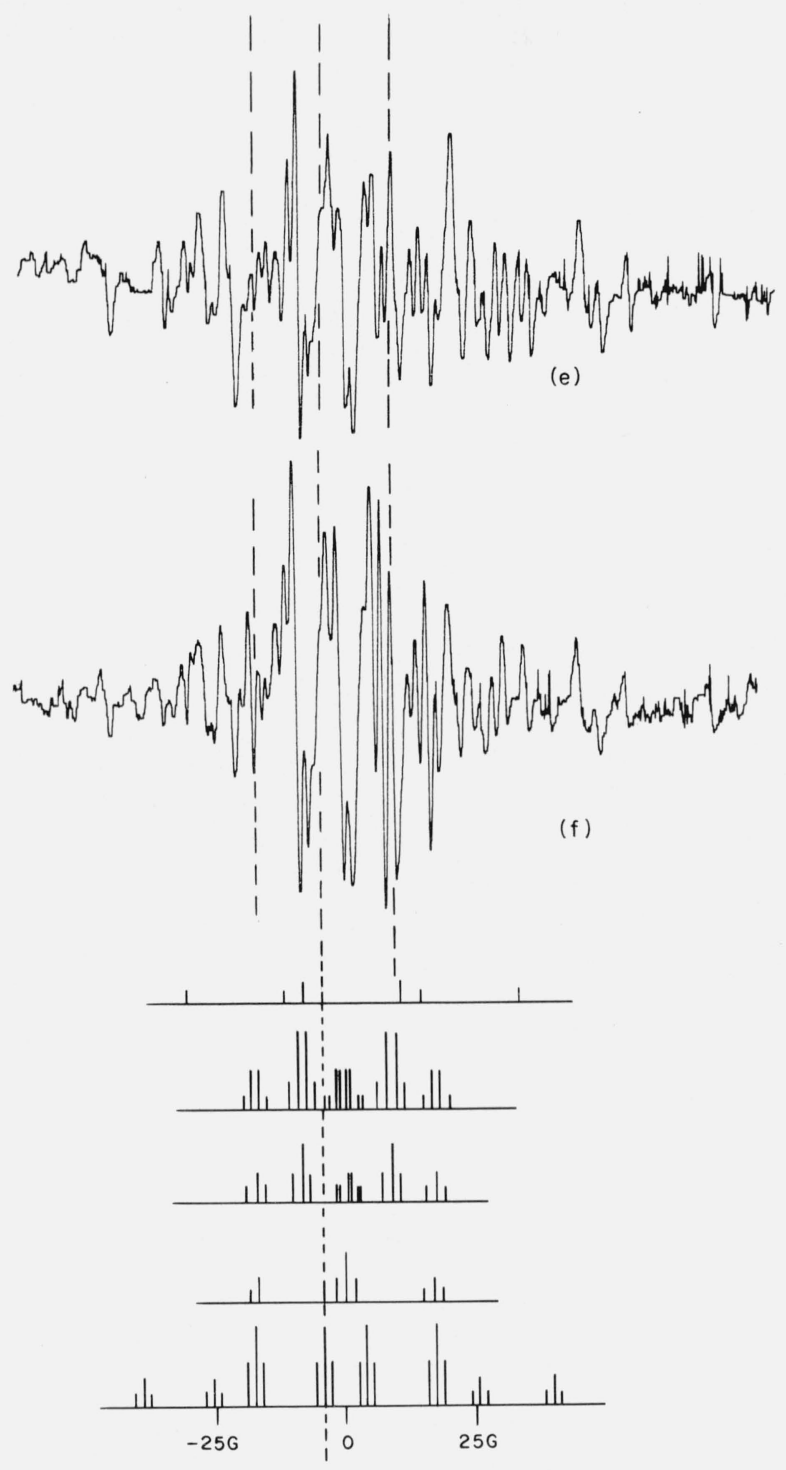

Figure 16-Continued

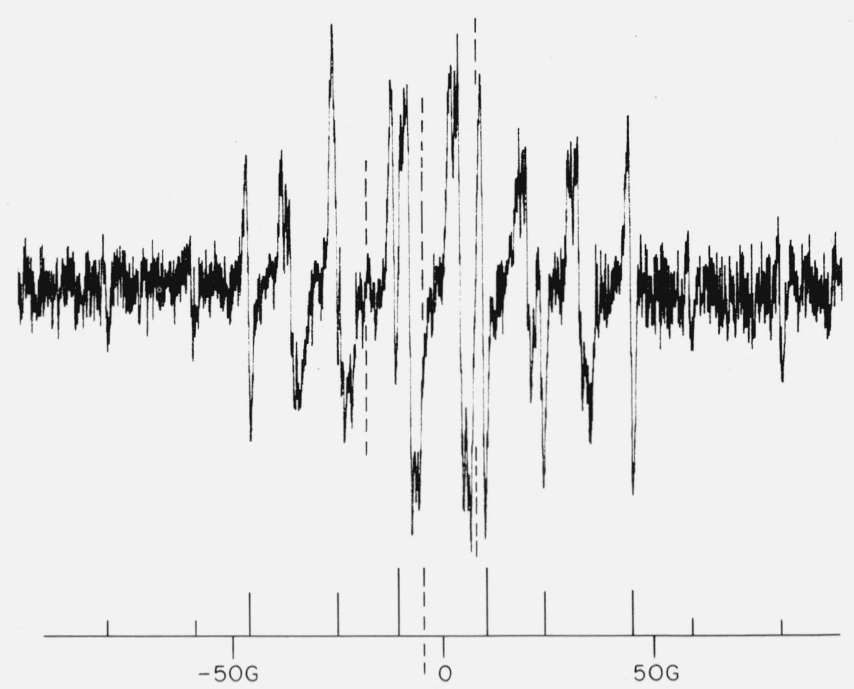

FiguRE 17. ESR spectrum from tetrahydrofuran $0.5 \mathrm{M}, 27^{\circ} \mathrm{C}, 7.4$ $\mathrm{cm}^{3} / \mathrm{sec}$.

Line scheme. $\mathrm{CH}_{2} \mathrm{CH}_{2} \dot{\mathrm{C}} \mathrm{HCH}_{2} \mathrm{O}_{-}$: for other lines see Ref. $4 . \cdots$ line positions of

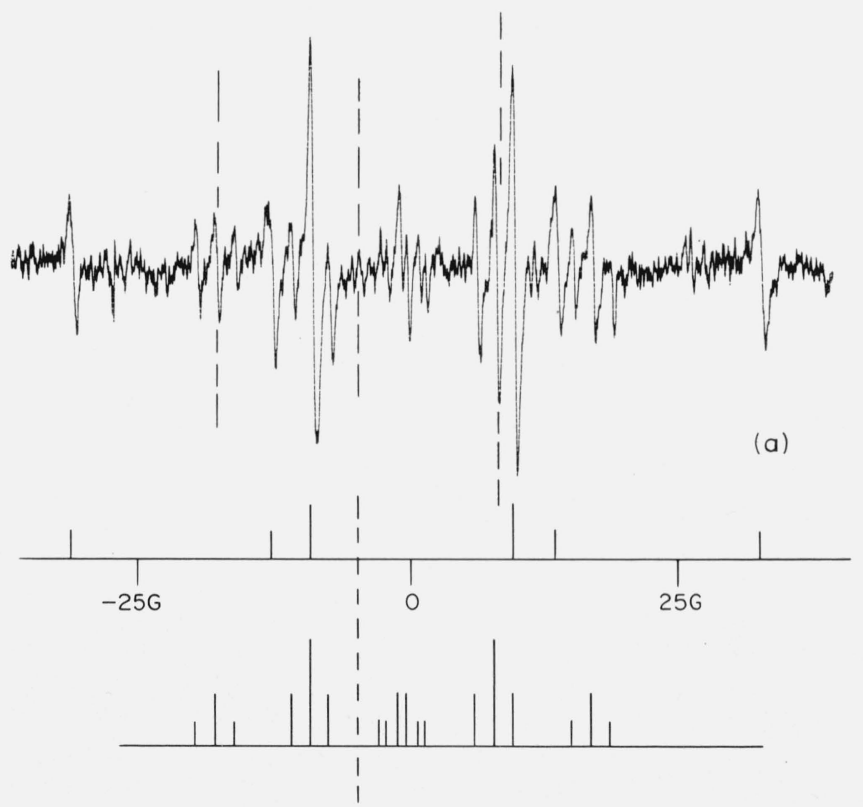

FIGURE 18. ESR spectra from vinyl ethyl ether and ethylene glycol monoethyl ether.

Upper spectrum (a) vinyl ethyl ether 0.04 V. $25{ }^{\circ} \mathrm{C}, 5.1 \mathrm{~cm}^{3} / \mathrm{sec}$. Line schemes: upper. $\mathrm{CH}_{2} \mathrm{CHOHOCH}_{2} \mathrm{CH}_{3}$ : lower. probable $\mathrm{HOCH}_{2} \mathrm{CHOCH}_{2} \mathrm{CH}_{3}$. Lower spectrum (b) ethylene glycol monoethyl ether $0.25 \mathrm{~V} .25{ }^{\circ} \mathrm{C} .7 .7 \mathrm{~cm}^{3} / \mathrm{sec}$. Line schemes: upper. $\mathrm{HOCHCH} \mathrm{OCH}_{2-}$ $\mathrm{CH}_{3}$, middle. $\mathrm{HOCH}_{2} \mathrm{CHOCH}_{2} \mathrm{CH}_{3}$, lower. $\mathrm{CH}_{3} \mathrm{CHOCH}_{2} \mathrm{CH}_{2} \mathrm{OH}$.... line pesitions of $\mathrm{NO}\left(\mathrm{SO}_{3}\right)_{2}$. 


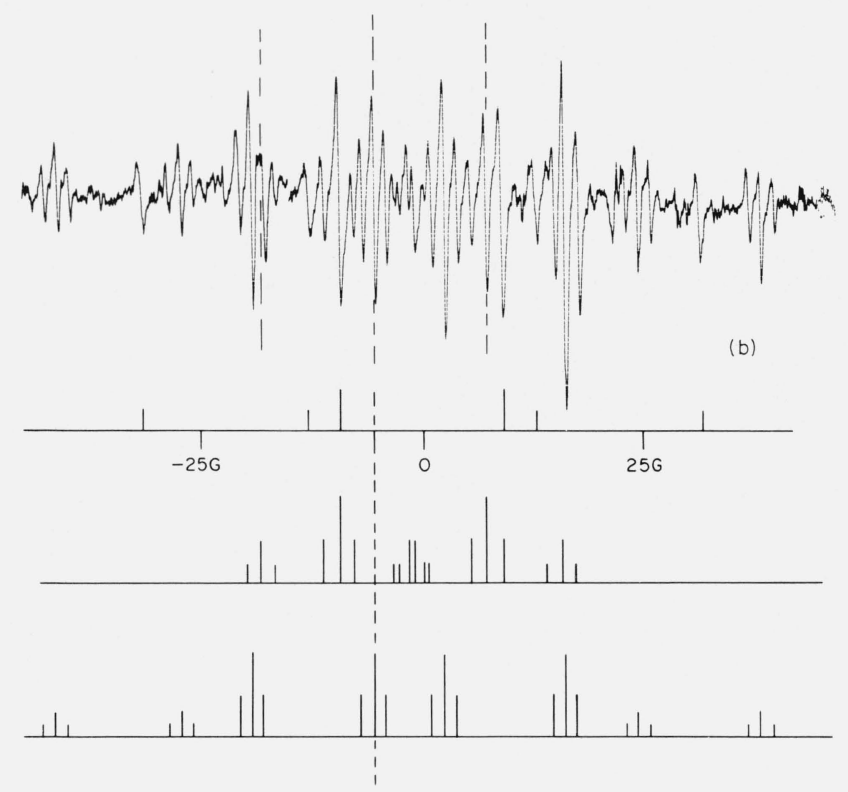

FigURE 18-Continued
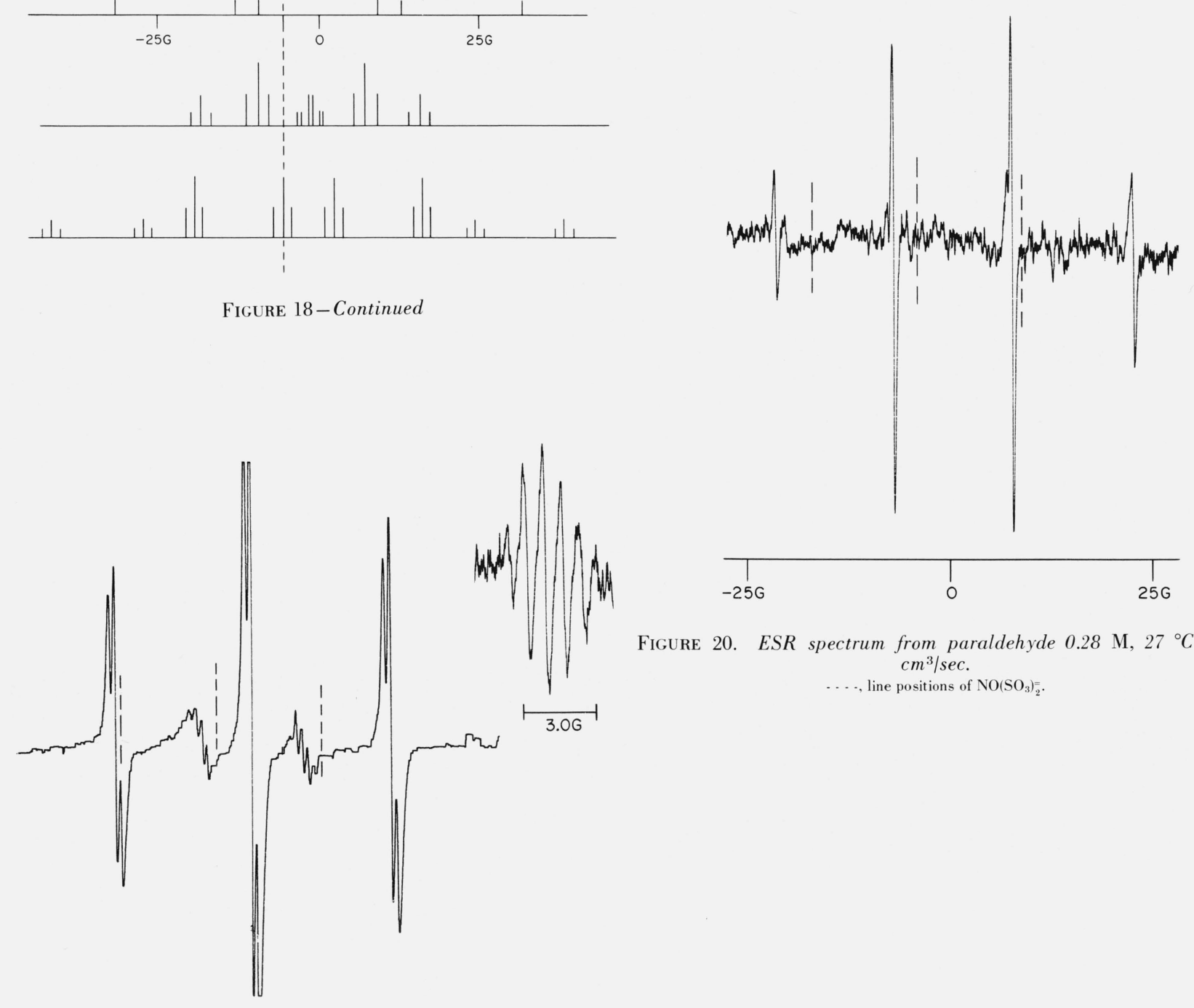

FigURE 20. ESR spectrum from paraldehyde $0.28 \mathrm{M}, 27{ }^{\circ} \mathrm{C}, 5.7$ $\mathrm{cm}^{3} / \mathrm{sec}$.

-..., line positions of $\mathrm{NO}\left(\mathrm{SO}_{3}\right)_{2}$.

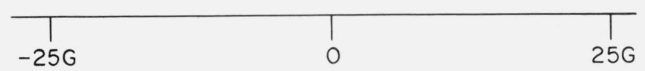

FIGURE 19. ESR spectrum from methylal.

Full spectrum, $0.25 \mathrm{M}, 27^{\circ} \mathrm{C}, 7.7 \mathrm{~cm}^{3} / \mathrm{sec}$. Inset, detail of faint lines at low magnetic field modulation: $0.5 \mathrm{M}, 27{ }^{\circ} \mathrm{C}, 5.7 \mathrm{~cm}^{3} / \mathrm{sec} \cdots$, line positions of $\left.\mathrm{NO}\left(\mathrm{SO}_{3}\right)_{2}\right)$. Strong triplet, $\mathrm{CH}_{2} \mathrm{OCH}_{2} \mathrm{OCH}_{3}$, weak doublet $\left(\mathrm{CH}_{3} \mathrm{O}\right)_{2} \dot{\mathrm{C}} \mathrm{H}$. 

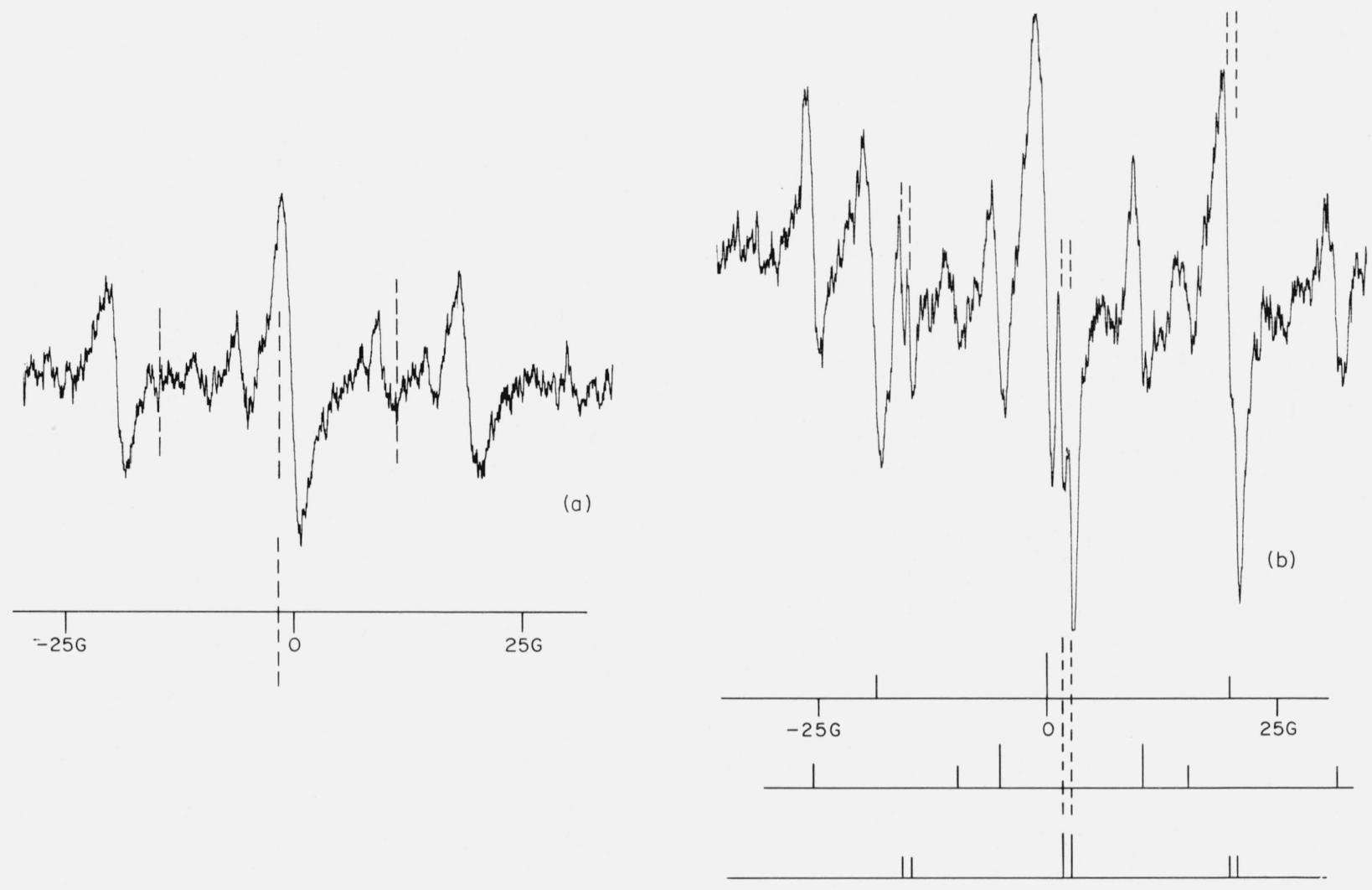

FIGURE 21. ESR spectra from ethylene glycol.

Spectrum, (a) $0.10 \mathrm{M} .25^{\circ} \mathrm{C}, 4.4 \mathrm{~cm}^{3} / \mathrm{sec}$. Spectrum, (b) mixture, ethylene glycol $0.5 \mathrm{M}$, methanol $0.1 \mathrm{M}$. temperature $25^{\circ} \mathrm{C}$, flow rate $5.9 \mathrm{~cm}^{3} / \mathrm{sec}$. Line schemes: upper, presumed $\dot{\mathrm{CH}}_{2} \mathrm{CHO}$, middle, unknown second component, lower $\dot{\mathrm{CH}}_{2} \mathrm{OH}$ from methanol. ..... line positions of $\mathrm{NO}\left(\mathrm{SO}_{3}\right) \overline{2}$. (spectrum (a)) and $\mathrm{CH}_{2} \mathrm{OH}$ (spectrum (b)). 


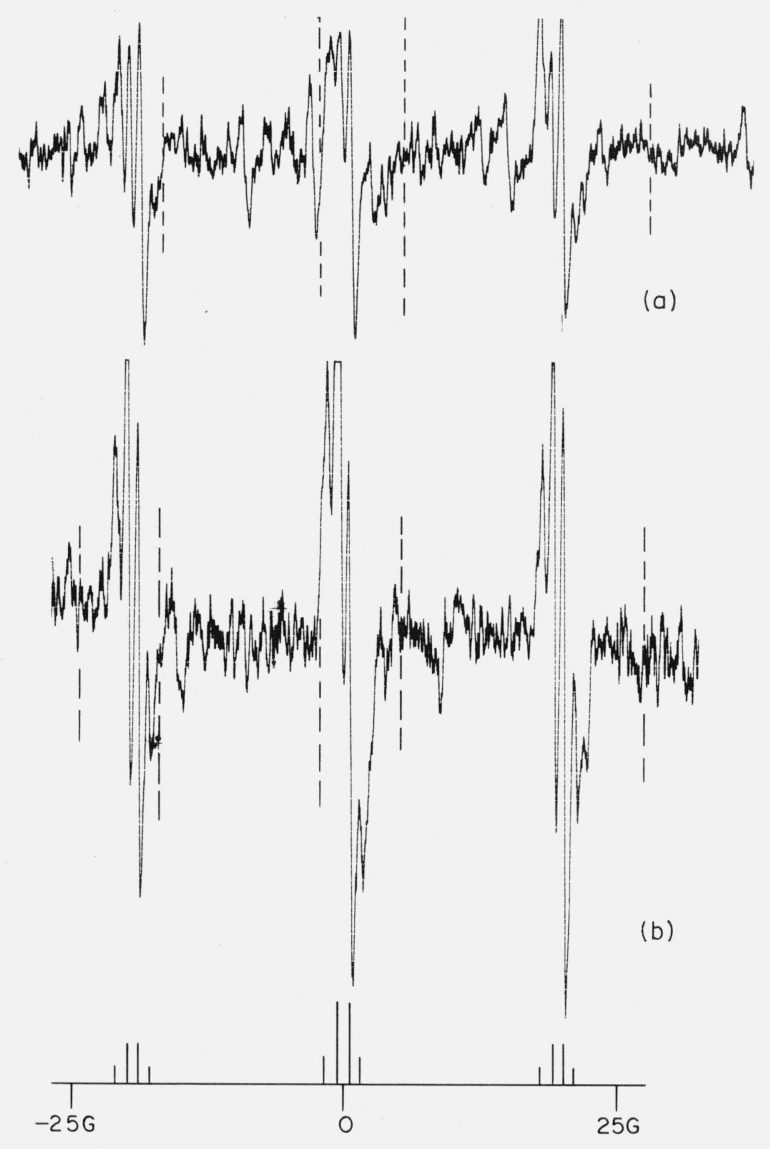

FIGURE 22. ESR spectra from propylene glycol and acetone.

Upper spectrum, (a) propylene glycol $1 \mathrm{M}, 25^{\circ} \mathrm{C}, 6.8 \mathrm{~cm}^{3} / \mathrm{sec}$. Lower spectrum, (b)

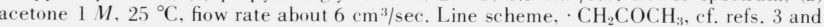
27. ...., high intensity line positions of $\mathrm{C}_{3} \mathrm{CHOH}$, from mixture experiments.

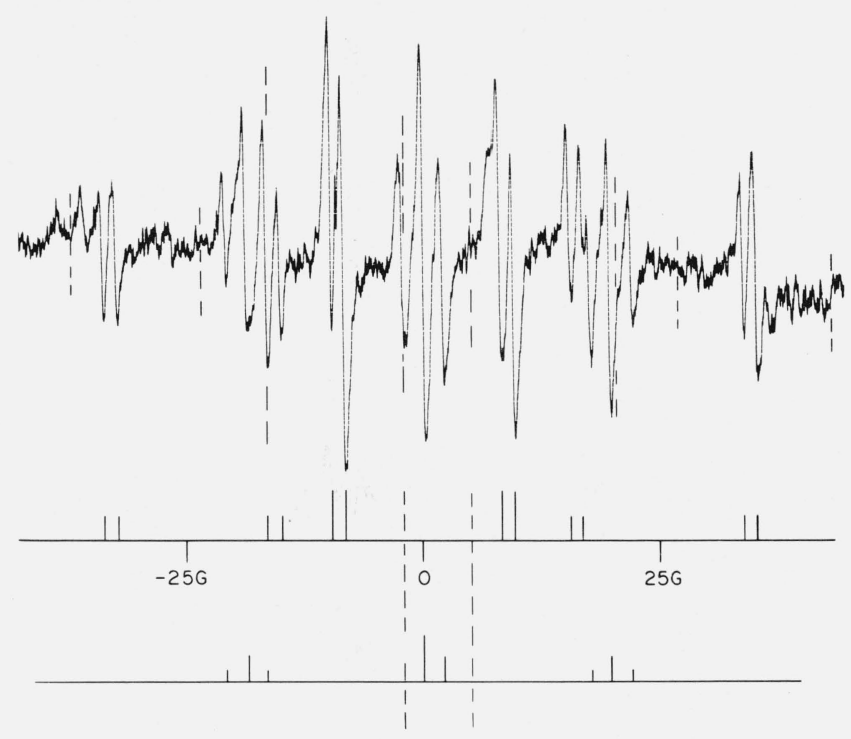

FigURE 23. ESR spectrum from glycerol $0.46 \mathrm{M}, 26{ }^{\circ} \mathrm{C}, 5.0 \mathrm{~cm}^{3} / \mathrm{sec}$.

Line schemes: upper, $\mathrm{CH}_{2} \mathrm{OHCHCHO}$ : lower, $\mathrm{CH}_{2} \mathrm{COCH}_{2} \mathrm{OH}$. . . . lines (in spectrum) and center lines (in line schemes) of $\mathrm{CH}_{3} \mathrm{CHOH}$ from mixture experiments.

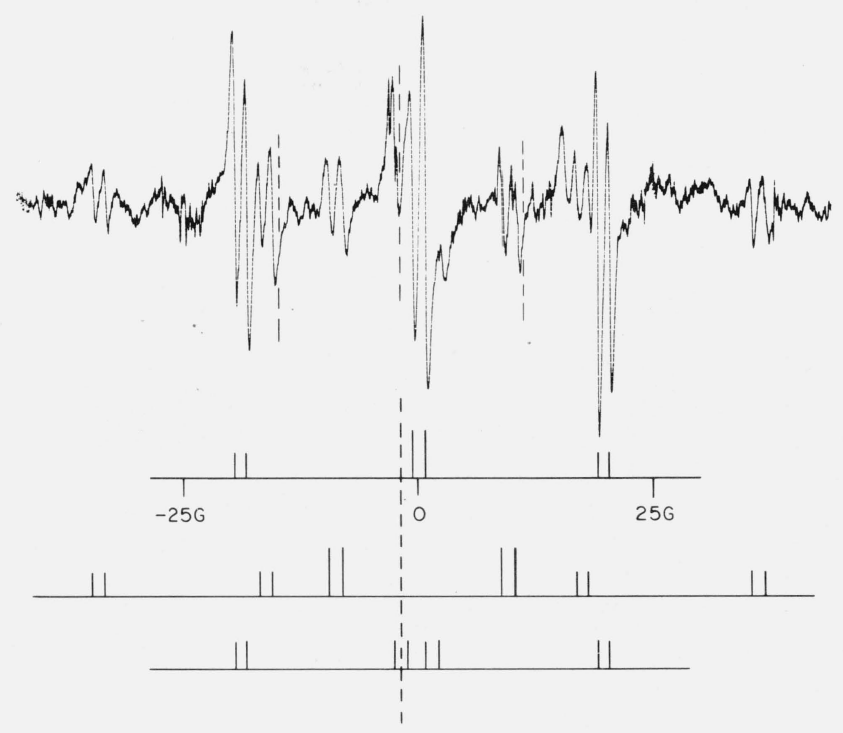

FIGURE 24. ESR spectrum from mannitol $0.11 \mathrm{M}, 21^{\circ} \mathrm{C}, 6.7 \mathrm{~cm}^{3} / \mathrm{sec}$. Line schemes tentative: upper. $\mathrm{CH}_{2} \mathrm{COCHOH}$ mand/or m $\mathrm{CHOHCHCOCHOH}$ (equal splittings), middle, $\mathrm{CH}_{2} \mathrm{OHCHCOCHOH}$, lower m $\mathrm{CHOHCHCOCHOH}$ (unequal splittings). .... lines of $\mathrm{NO}\left(\mathrm{SO}_{3}\right)$ 

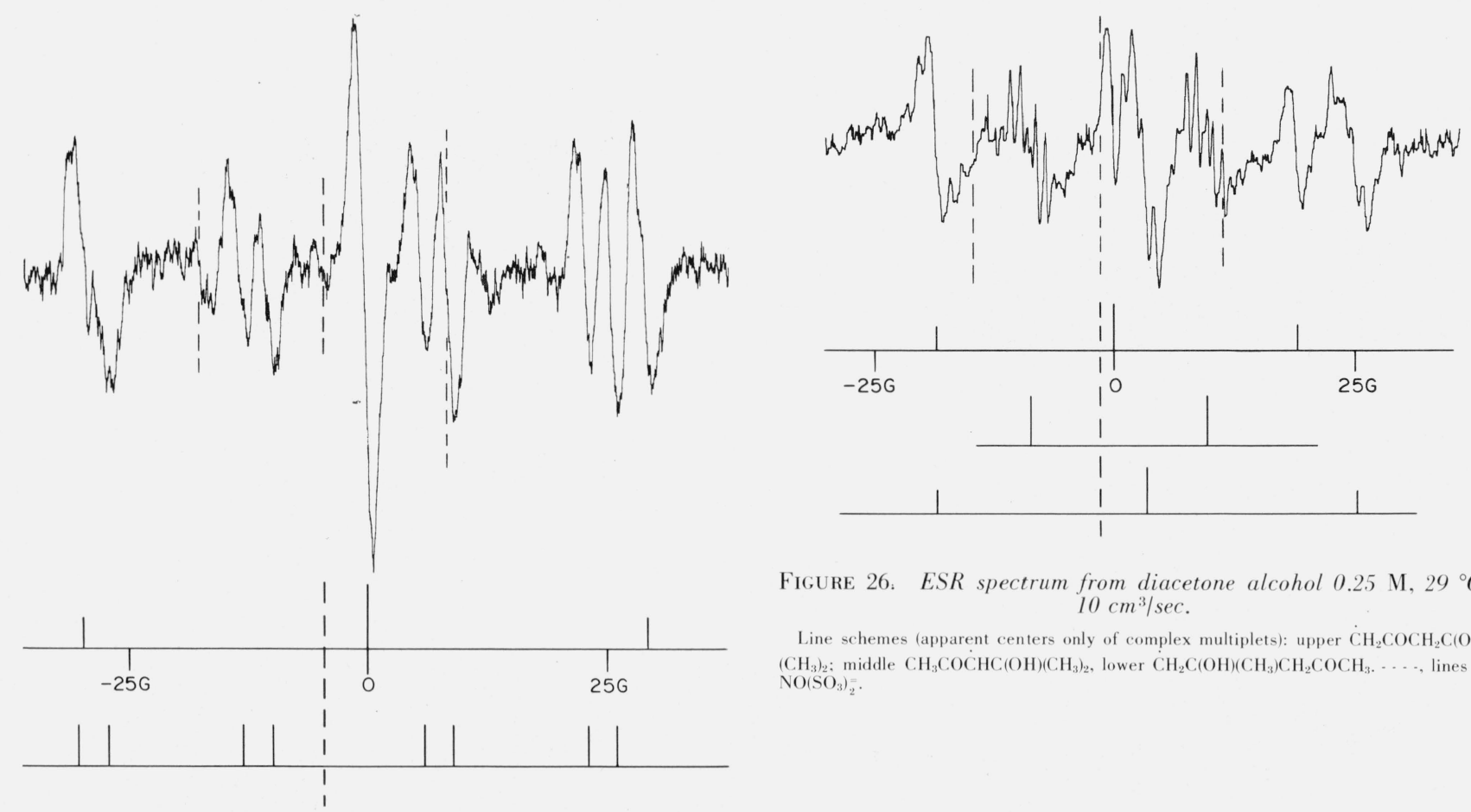

Figure 26: ESR spectrum from diacetone alcohol $0.25 \mathrm{M}, 29{ }^{\circ} \mathrm{C}$, $10 \mathrm{~cm}^{3} / \mathrm{sec}$

Line schemes (apparent centers only of complex multiplets): upper $\mathrm{CH}_{2} \mathrm{COCH}_{2} \mathrm{C}(\mathrm{OH}$ $\left(\mathrm{CH}_{3}\right)_{2}$ : middle $\mathrm{CH}_{3} \mathrm{COCHC}(\mathrm{OH})\left(\mathrm{CH}_{3}\right)_{2}$, lower $\mathrm{CH}_{2} \mathrm{C}(\mathrm{OH})\left(\mathrm{CH}_{3}\right) \mathrm{CH}_{2} \mathrm{COCH}_{3} \ldots$, lines of $\mathrm{NO}\left(\mathrm{SO}_{3}\right)_{2}=$

FIGURE 25. ESR spectrum from inositol $0.1 \mathrm{M}, 25^{\circ} \mathrm{C}, 4.2 \mathrm{~cm}^{3} / \mathrm{sec}$.

Line schemes: upper, m $\mathrm{CHOHCOHCHOH}$ m, lower, m $\mathrm{CHOHCOCHCHOH} w . . .$. lines of $\mathrm{NO}\left(\mathrm{SO}_{3}\right)_{2}$.

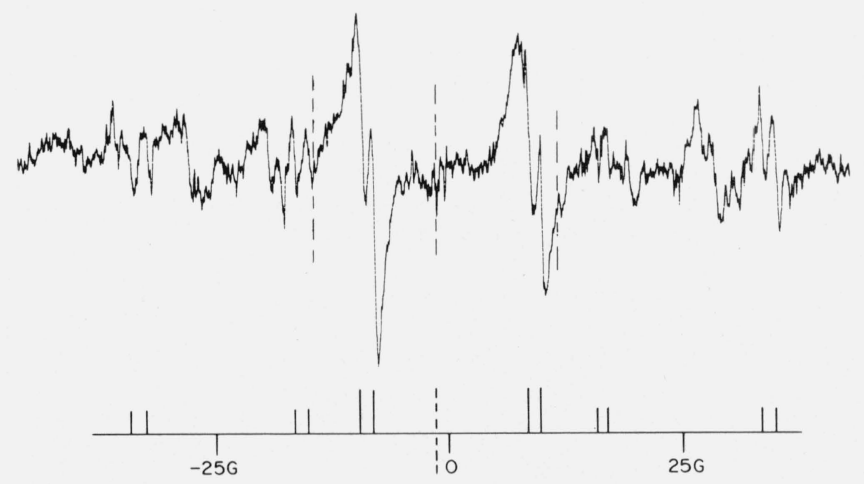

FIGURE 27. ESR spectrum from acrolein $0.037 \mathrm{M}, 21^{\circ} \mathrm{C}, 5.9 \mathrm{~cm}^{3} / \mathrm{sec}$. $\mathrm{H}_{2} \mathrm{O}_{2} 0.025 \mathrm{M}, \mathrm{H}_{2} \mathrm{O}_{2}$ and monomer in separate reservoirs, fed via $\mathrm{Y}$-connection. Line scheme: $\mathrm{HOCH}_{2} \mathrm{CHCHO}$ (cf. fig. 23, glycerol), applies to minor narrow-line components only, ..... line positions of $\mathrm{NO}\left(\mathrm{SO}_{3}\right)_{2}$. 

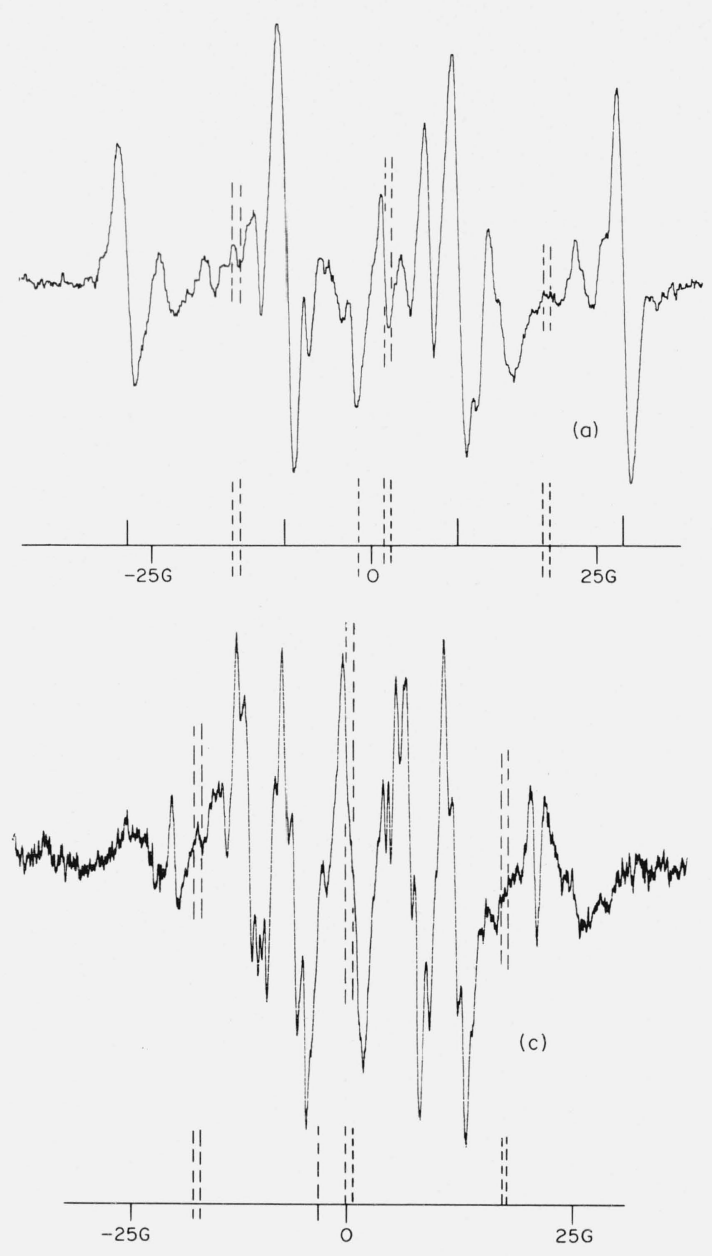
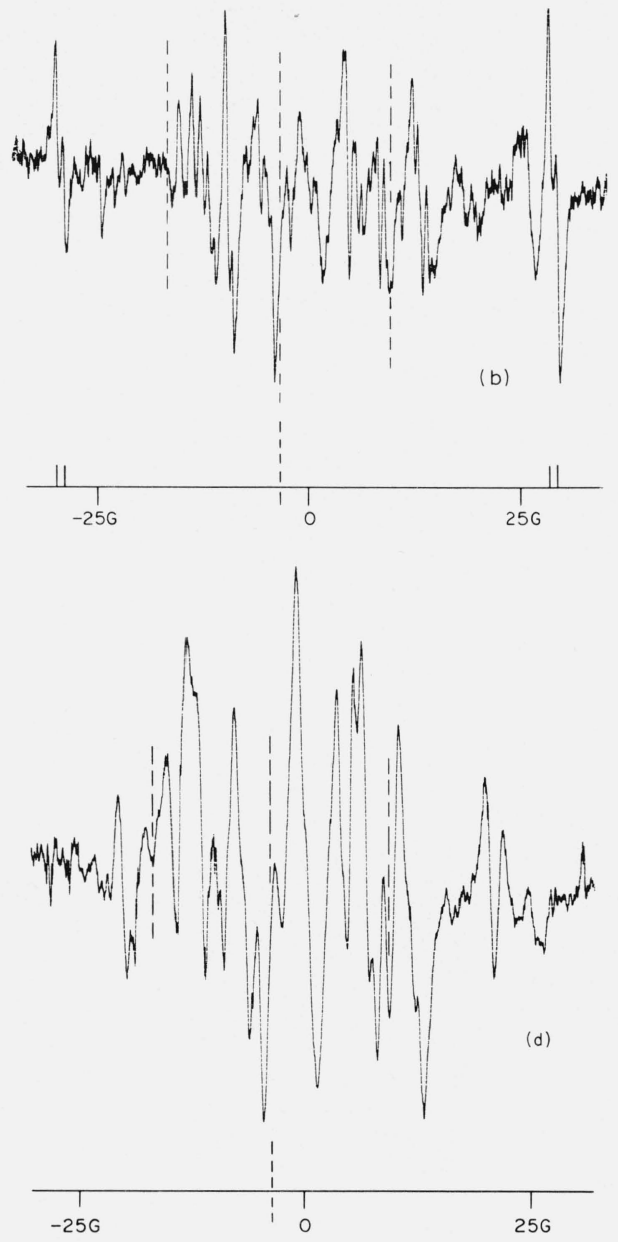

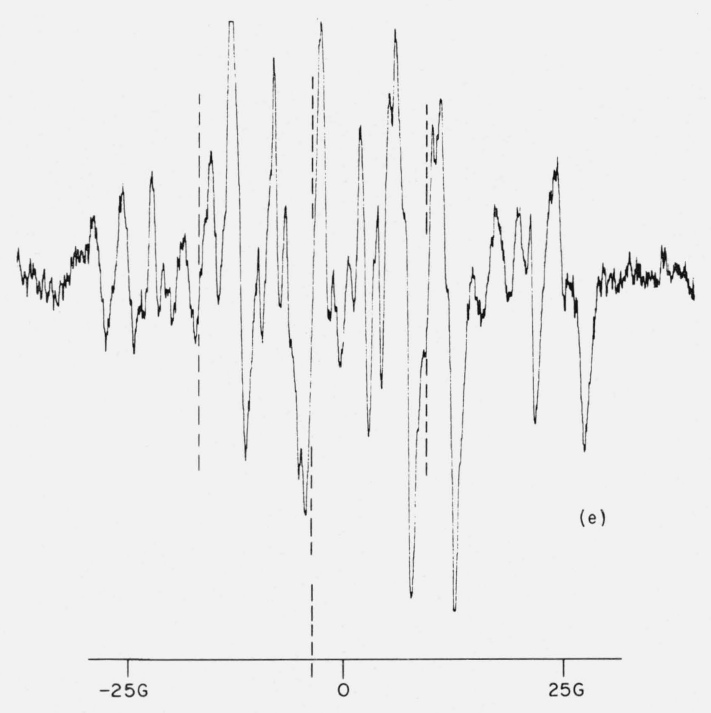

FIGURE 28. ESR spectra of simple and polymeric carbohydrates.

(a) Dextran $0.1 \mathrm{M} .27{ }^{\circ} \mathrm{C}, 4.2 \mathrm{~cm}^{3} / \mathrm{sec}$. Line scheme: four most prominent lines, possibly a single spectrum of type m $\mathrm{CHOH}($ axial $\mathrm{H})-\dot{\mathrm{CH}}-\mathrm{CO}-\mathrm{CHOH} m$.

b) Clucose $0.39 \mathrm{M} 27^{\circ} \mathrm{C} .7 .6 \mathrm{~cm}^{3} / \mathrm{sec}$. Line scheme: outermost line pairs only (c) Commercial corn dextrin $0.5 \mathrm{M} .27^{\circ} \mathrm{C} .8 \mathrm{~cm}^{3} / \mathrm{sec}$ (d) Soluble starch (for iodimetry) $0.13 \mathrm{M} .24^{\circ} \mathrm{C} .5 .2 \mathrm{~cm}^{3} / \mathrm{sec}$; higher magnetic field modulation than C. (e) Maltose $0.05 \mathrm{M.} 24^{\circ} \mathrm{C}, 5.7 \mathrm{~cm} / / \mathrm{sec}$.

Maltose $-\mathrm{H}_{2} \mathrm{O}_{22}$ reservoir at $4{ }^{\circ} \mathrm{C} . \ldots$, reference lines of $\mathrm{CH}_{2} \mathrm{OH}$ and $\mathrm{NO}\left(\mathrm{SO}_{3}\right)=$. Scales and line schemes carry center line of $\mathrm{NO}\left(\mathrm{SO}_{3}\right)_{2}$ as single line. Magnetic field scales roughly corrected for nonlinearity. 


\subsection{Alcohols and Polyvinyl Alcohol}

\section{a. Methanol and Ethanol}

The only simple alcohols examined here were ethanol and methanol, for use as reference spectra, and 2-buten-1,4-diol. Many others are reported in the literature $[2,9]$. The fairly accurate values of table 1 are compared with the most accurate values in the literature, obtained by photolysis. While discrepancies in absolute values of $a_{\alpha}, a_{\beta}$, and $g$ could easily be within the uncertainties of our reference material, the nitrosodisulfonate ion, a real difference is seen in the $\mathrm{CH}_{3} \dot{\mathrm{C}} \mathrm{HOH}$ spectra. The index least sensitive to our errors is the ratio $\left(a_{\beta}-a_{\alpha}\right) / a_{\alpha}$, which is $0.498 \pm .003$ in our experiment at $25 \pm 1{ }^{\circ} \mathrm{C}$, and 0.456 in the photolysis at $26{ }^{\circ} \mathrm{C}[9]$.

\section{b. 2-Buten-1,4-diol}

2-Buten-1,4-diol gave two spectra, figure 1. The strong lines correspond to the radical formed by addition:

\section{$\mathrm{HOCH}_{2} \mathrm{CHOHC}_{\mathrm{C}} \mathrm{HCH}_{2} \mathrm{OH}$}

\section{$\begin{array}{llll}1 & 2 & 3 & 4\end{array}$}

with the assignment $a_{3}(\alpha)=21.5 \quad \mathrm{G}, \quad a_{4}(\beta)=22.5$, $a_{2}(\beta)=17.5$, and $g=2.0023 \pm 0.0005$. It is conceivable that $a_{3}$ and $a_{2}$ should be interchanged, although a low $a_{\alpha}$ is unusual when the position has no oxygen-bearing substituents.

TABLE 1. Radicals from alcohols

\begin{tabular}{|c|c|c|c|c|}
\hline Substrate and radical & $a_{\alpha}, \mathrm{G}$ & $a_{\beta}, \mathrm{G}$ & $a_{\mathrm{OH}}, \mathrm{G}$ & $g$ \\
\hline $\begin{array}{l}\text { Methanol } \\
\cdot \mathrm{CH}_{2} \mathrm{OH} \ldots\end{array}$ & $17.43 \pm 0.05$ & & 0.90 & 2.00320 \\
\hline$\cdot \mathrm{CH}_{2} \mathrm{OH}^{\mathrm{a}} \ldots \ldots \ldots \ldots \ldots \ldots$ & 17.38 & & 1.15 & $\begin{array}{r} \pm 0.00004 \\
2.00334\end{array}$ \\
\hline $\begin{array}{l}\text { Ethanol } \\
\mathrm{CH}_{2} \dot{\mathrm{C}} \mathrm{HOH}\end{array}$ & & & & \\
\hline $\mathrm{CH}_{3} \mathrm{CHOH}_{3} \mathrm{CHOH}^{\mathrm{a}}$ & $\begin{array}{l}14.91 \pm 0.1 \\
15.37\end{array}$ & $\begin{array}{l}22.5 \pm .1 \\
22.19\end{array}$ & $\begin{array}{l}0 \\
0\end{array}$ & $\begin{array}{r}2.0001 \\
\pm 0.0001 \\
2.00323\end{array}$ \\
\hline 2-Buten-1,4-diol & & & & \\
\hline $\mathrm{HOCH}_{2} \mathrm{CHOHC}_{\dot{C}} \mathrm{HCH}_{2} \mathrm{OH} \ldots$ & 21.5 & $\begin{array}{l}22.5 \mathrm{CH}_{2} \mathrm{OH} \\
17.5 \mathrm{CHOH}\end{array}$ & & $\begin{array}{r}2.0023 \\
\pm 0.0010\end{array}$ \\
\hline $\mathrm{HOC} \mathrm{CCH}=\mathrm{CHCH}_{2} \mathrm{OH}^{\mathrm{c}} \ldots \ldots$ & (b) & (b) & & $\begin{array}{r}2.0029 \\
\pm 0.0010\end{array}$ \\
\hline $\begin{array}{l}\text { Polyvinyl alcohol } \\
\text { muCHOHC̈HCHOH } m \text {........... }\end{array}$ & $22.0 \pm 0.2$ & $15.7 \pm 0.2$ & & $\begin{array}{r}2.0022 \\
\pm 0.0002\end{array}$ \\
\hline $\begin{array}{c}m \mathrm{CH}_{2} \dot{\mathrm{C}}(\mathrm{OH}) \mathrm{CH}_{2} m v \\
\text { or } m \sim \mathrm{CH}_{2} \dot{\mathrm{C}} \mathrm{HOH}\end{array}$ & (b) & () & & 2.0029 \\
\hline
\end{tabular}

a Reference [9].

${ }^{\mathrm{c}}$ Identity not established.

A weaker spectrum at a $g$-value 0.0006 higher shows lines at \pm 11.7 and $\pm 15.3 \mathrm{G}$ from its center and weaker lines at \pm 8.1 and $\pm 10.7 \mathrm{G}$. The $g$-value suggests that it could be the spectrum of $\mathrm{HOC} H C H=\mathrm{CHCH}_{2} \mathrm{OH}$ formed by abstraction. Since the analogous radical $\mathrm{HOC} \mathrm{CCH}=\mathrm{CH}_{2}$ has splittings near $13 \mathrm{G}$ for its end hydrogens and $3 \mathrm{G}$ for the middle one [9], the present spectrum presumably contains hidden lines in its central region. Little more can be said because of the uncertainty regarding splittings from the $\mathrm{CH}_{2} \mathrm{OH}$ group.

The strong-line spectrum was also obtained from the mixing of ferrous sulfate, hydrogen peroxide and butenediol, but at low intensity and with lines greatly broadened.

\section{c. Polyvinyl Alcohol}

Polyvinyl alcohol produced radicals less easily than the simple alcohols, a concentration of $0.2 \mathrm{M}$ being required to minimize the hydroxyl peak. At this concentration the mixer clogged progressively with gel, so that complete spectra could be obtained only at relatively high scan rates and flow rates. The observed spectrum, figure 2, appears to consist of two components: (1) A system of six lines which fit the parameters $g=2.0022 \pm 0.0002, a$ (doublet) $=22.0 \pm 0.2 \mathrm{G}$ (one proton), $a$ (triplet) $=15.7 \pm 0.2 \mathrm{G}$ (two protons); and (2) a set of three lines, intensity about $1: 2: 1$, with separation $29.0 \pm 0.3 \mathrm{G}$ and $g=2.0029 \pm 0.0002$. The relative intensities of (2) and (1) varied with flow rate and temperature. In (1), the lines of double intensity appear at unit height but greater breadth, suggesting that the two equivalent protons may really differ by about $0.5 \mathrm{G}$. The radicals which could be formed by abstraction and subsequent splitting of the parent radical are<smiles>CCC(O)CCCC(C)Br</smiles>

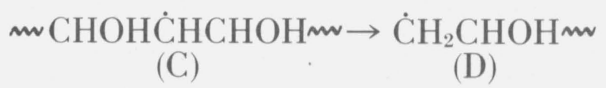

The published $g$-values of radicals derived from alcohols [9], as well as some obtained in the present work, indicate that $g$ should be near 2.0030 for (A) and (B) and nearer 2.0024, as in hydrocarbon radicals for (C) and (D). Therefore, by $g$-value analogy, the radical responsible for spectrum 1 could be (C) or (D). Of these two, (D) requires that the two equivalent protons (15.7-G triplet splitting) should be in the $\alpha\left(\mathrm{CH}_{2}\right)$ position. The $\alpha$ splittings for radicals of this type do not seem to be subject to much variation from values in the neighborhood of 20 to $22 \mathrm{G}[2,8,9]$, so the low splitting for this position is improbable: moreover, the imperfect equivalence suggested by line breadths is improbable for structure (D), in which rotation about the $\mathrm{C}-\mathrm{C}$ bond should be free. Radical I is therefore most likely (C), m ${ }^{m} \mathrm{CHOH} \dot{\mathrm{C}} \mathrm{HCHOH} m$. Although the low value for the triplet $(\beta)$ splitting may seem suspicious (cf. $a_{\beta}=28 \mathrm{G}$ in $\dot{\mathrm{C}} \mathrm{H}_{2} \mathrm{CH}_{2} \mathrm{OH}$ [9]), the range of variation encountered is great especially if there are favored positions in rotation about the $\mathrm{C}-\mathrm{C}$ bonds, and similar low splittings are encountered in certain carboxylic acid radicals [3, 8]. Some form of steric hindrance is most likely responsible for the discrimination against the normally favored $\mathrm{CHOH}$ abstraction. The absolute rate of radical formation is in any 
event lower than usual, as judged by the persistence of hydroxyl.

The identification of spectrum 2 is uncertain. The $g$-value is consistent with A or B, but the hyperfine structure forbids $\mathrm{B}$, which can have no central line, and is inconsistent with $\mathrm{A}$ also. Although additional lines could be present beyond $29 \mathrm{G}$, or hidden at \pm 10 , \pm 16 , or $\pm 26 \mathrm{G}$, the observed splitting of the $29 \mathrm{G}$ lines seems too great for the intermediate lines of a 1:4:6:4:1 intensity pattern and too small for the end lines. If, in $\mathrm{A}$, the $\beta$ protons occur in two pairs with distinct splittings $a^{\prime}$ and $a^{\prime \prime}$, in a 9-line pattern, the $29 \mathrm{G}$ splitting could be equal to the sum $a^{\prime}+a^{\prime \prime}$ but is too great for $a^{\prime}-a^{\prime \prime}$.

\subsection{Acids}

Except for a $g$-value determination on acetic acid radicals, no simple acids were examined, as the literature is adequate $[3,8]$. The $g$ value of $\dot{\mathrm{C}} \mathrm{H}_{2} \mathrm{COOH}$ is extremely close to that of $\dot{\mathrm{C}} \mathrm{H}_{2} \mathrm{OH}$, even with allowances for second-order shift. The splitting $a$, table 2, is based on simultaneous spectra of $\dot{\mathrm{C}} \mathrm{H}_{2} \mathrm{OH}$ and $\dot{\mathrm{C}} \mathrm{H}_{2} \mathrm{COOH}$ and $\dot{\mathrm{C}} \mathrm{H}_{2} \mathrm{OH}$ and $\mathrm{NO}\left(\mathrm{SO}_{3}\right)_{2}^{=}$and may be more accurate than the published value.

TABLE 2. Radicals from acids

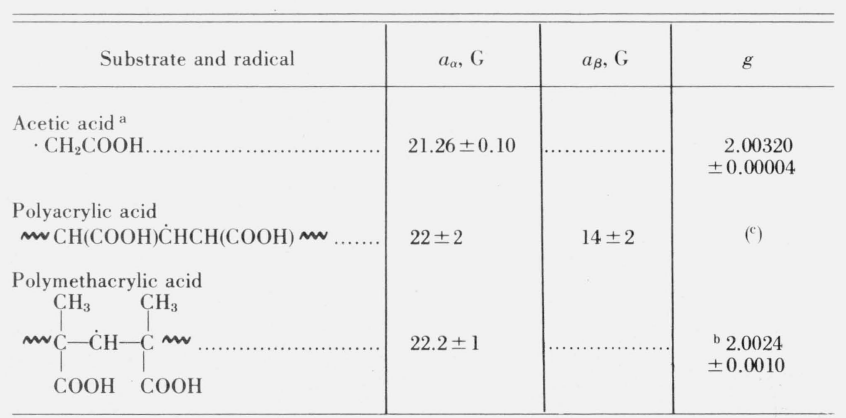

${ }^{a}$ Cf. Reference [3].

${ }^{\mathrm{b}}$ Method 4, OH position.

c Unsatisfactory spectrum, weak, unsymmetrical.

\section{a. Polyacrylic Acid}

Like the simple aliphatic acids [3], the polymer acids showed only hydroxyl at low concentrations. At $0.25 M$ radical spectra were obtained, although hydroxyl was still present.

The spectrum of polyacrylic acid, figure 3 , table 2 , was of poor quality and difficult to obtain because of clogging of orifices by gel. The overall asymmetry indicates two or more radicals of differing $g$.

The chemistry of abstraction from aliphatic acids [3] suggests that the most probable initial radical should be,<smiles>CC(C=O)C(=O)O</smiles>

For this radical the choice of $a_{\alpha}=22 \mathrm{G}, a_{\beta}=14 \mathrm{G}$ would account for the strong lines at $\pm 11 \mathrm{G}$ and $\pm 25 \mathrm{G}$, provided central lines at $\pm 3 \mathrm{G}$ are obscured by the central line of another radical. Remaining lines do not constitute a complete enough set even for speculation. It is certain that Fischer's radical [8], $m \mathrm{CH}_{2} \dot{\mathrm{C}} \mathrm{HCOOH}$, is not present in appreciable amounts as the requisite lines at \pm 32.32 or $\pm 32.65 \mathrm{G}$ are absent; this radical, if present, would have been a likely product from the degradation of an alternate species,<smiles>CCC(C=C(CCCCC(CC)C(=O)O)C(=O)O)C(=O)O</smiles><smiles>CC(C[C@H](C)C=CCCCCC(=O)O)C(=O)O</smiles>

\section{b. Polymethacrylic Acid}

This acid, figure 4, Table 2, gave a simple spectrum of two rather broad lines, readily identified as<smiles>CC(C)(C)C(C)(C)C(=O)O</smiles>

$a_{\alpha}=22.2 \mathrm{G}$, with the $\gamma$-splitting from two $\mathrm{CH}_{3}$ and two $\mathrm{CH}_{2}$ groups unresolved, peak width between derivative maxima $5.5 \mathrm{G}$ and $g=2.0024 \pm 0.0010$. Again, central and outer lines $( \pm 23.6 \mathrm{G})$ of the radical<smiles>CCC(C)C(=O)O</smiles>

found during polymerization [8] were not detected.

\subsection{Amines and Amides}

In acid solution the lower amines are not attacked by hydroxyl, presumably because of the strong deactivating influence of the positively charged ammonium nitrogen [3]. However, when the final $p \mathrm{H}$ was between 7 and 9, radical ESR spectra, figures 5 to 8, were obtained from the secondary amines polyethylene imine, dimethylamine, and diethylamine, when mixed with hydrogen peroxide and either titanium trichloride or ceric ammonium sulfate. No spectra were obtained in highly alkaline titanium-peroxide systems, nor from ammonia, methylamine, trimethylamine or pyridine. With the ceric sulfate-hydrogen peroxide system the spectra were relatively simple and their structure the same at $p \mathrm{H} 7$ and $p \mathrm{H} 8$. With the titanium trichloride-hydrogen peroxide system the spec- 
tra varied: at $p \mathrm{H} 7$ and low flow rate, which also resulted in relatively low intensity, they approached the simple structure obtained with ceric ammonium sulfate, while at $p \mathrm{H} 8$ to 8.5 and high flow rate they contained many additional lines, figures 6 to 8 . Besides $p \mathrm{H}$ and flow rate, the age of the peroxide amine solution may have been an important factor governing spectral intensity and complexity; for example, in figure 8 the intensities of symmetrically related peaks increased with time, i.e., toward the left of the figure.

We believe that the sharper lines of figure 5 and the simpler spectra of figures 7 and 8 are the spectra of nitroxides $[13,18]$. The hyperfine splitting parameters, table 3 , are compatible with either $R_{2} N$ or $R_{2} N O$. Considerations of lifetime and $g$-values favor the latter. The $g$-values in table 3 , for diethylamine and dimethylamine radicals, involve a large uncertainty. More exact values, determined with the $\mathrm{Ce}^{4+}-\mathrm{H}_{2} \mathrm{O}_{2}$ system, are 2.0055 for the dimethylamine radical and 2.0054 for the diethylamine radical. These values and the closely determined $g=2.0058$ for the polyethylene imine radical are near to the value for nitrosodisulfonate, 2.0055, and considerably higher than that reported for $\mathrm{NH}_{3}^{+}, 2.0034[20,21]$.

The $\mathrm{Ce}^{4+}-\mathrm{H}_{2} \mathrm{O}_{2}$ system at $p \mathrm{H} 8.5$ was studied only at flow rates of 3 to $5 \mathrm{~cm}^{3} / \mathrm{sec}$ and it is known only

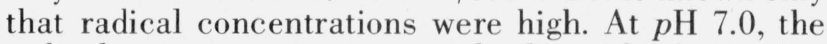
radical concentration grew slowly with decreasing flow rate to $0.1 \mathrm{~cm}^{3} / \mathrm{sec}$, and when flow was stopped remained nearly steady with lifetimes of several minutes for the dimethylamine system and over 20 $\mathrm{min}$ in the diethylamine system. These long lifetimes seem unlikely for ordinary free radicals.

TABLE 3. Radicals from amines

\begin{tabular}{|c|c|c|c|c|}
\hline Substrate and radical & $a_{\mathrm{N}}, \mathrm{G}$ & $a_{\beta}, \mathrm{G}$ & $g$ & Other \\
\hline $\begin{array}{l}\text { Diethylamine }\left(\mathrm{CH}_{3} \mathrm{CH}_{2}\right)_{2} \mathrm{~N} \cdot \text { or } \\
\mathrm{Et}_{2} \mathrm{NO} \text {. }\end{array}$ & 17.0 & 12.3 & $2.0044 \pm 0.001$ & $a_{\mathrm{CH}_{3}}^{\mathrm{H}}<0.5 \mathrm{G}$ \\
\hline $\begin{array}{l}\text { Dimethylamine }\left(\mathrm{CH}_{3}\right)_{2} \mathrm{~N} \cdot \text { or } \\
\left(\mathrm{CH}_{3}\right)_{2} \mathrm{NO} \text {. }\end{array}$ & 17.0 & 14.8 & $2.0044 \pm .001$ & \\
\hline $\begin{array}{l}\text { Polyethylene imine } \mathrm{m}_{\mathrm{CH}_{2}} \mathrm{NCH}_{2} m \text { r } \\
\text { or } m \mathrm{CH}_{2} \mathrm{NCH}_{0} m \text {. }\end{array}$ & 14.7 & 12.7 & 2.0058 & \\
\hline Ammonium salts $\mathrm{NH}_{3}^{+}(\mathrm{S})^{\mathrm{a}}$ & 18.1 & & 2.0034 & \\
\hline
\end{tabular}

a References [18, 19].

If the simple spectra are those of nitroxide radicals, the mechanism of formation may be rather direct in the $\mathrm{Ce}^{4+}-\mathrm{H}_{2} \mathrm{O}_{2}$ system at high $p \mathrm{H}$ and high flow rate:

$$
\mathrm{R}_{2} \mathrm{NH}+\mathrm{HO}_{2} \cdot \rightarrow \mathrm{R}_{2} \mathrm{NO} \cdot+\mathrm{H}_{2} \mathrm{O}
$$

or

$$
\mathrm{R}_{2} \mathrm{NH}+\mathrm{O}_{2}^{-} \rightarrow \mathrm{R}_{2} \mathrm{NO} \cdot+\mathrm{OH}^{-}
$$

In the $\mathrm{Ti}^{3+}-\mathrm{H}_{2} \mathrm{O}_{2}$ system, some experiments indicate that the amine and hydrogen peroxide must be in contact for 10 to $30 \mathrm{~min}$ before the experiment. In this case the stable precursor of the observed radicals could be the dialkylhydroxylamine $\mathrm{R}_{2} \mathrm{NOH}$, which can be formed in good yields from the amine $\mathrm{R}_{2} \mathrm{NH}$ and $\mathrm{H}_{2} \mathrm{O}_{2}$ [22].

$$
\mathrm{R}_{2} \mathrm{NOH}+\dot{\mathrm{O}} \mathrm{H} \rightarrow \mathrm{H}_{2} \mathrm{O}+\mathrm{R}_{2} \dot{\mathrm{NO}}
$$

The species responsible for the extra lines is uncertain. The overall symmetry of the composite spectra indicates essentially the same $g$-value for the two species. In the spectrum from dimethylamine, figure 8 , the frequent occurrence of lines about midway between lines of the simple spectrum suggests an odd number of equivalent protons. A conceivable structure is $\overline{\mathrm{C}} \mathrm{H}_{2} \mathrm{NOCH}_{3}$ which could be produced by slow Cionization of $\mathrm{CH}_{3} \mathrm{NOCH}_{3}$; however, the possibility of numerous hidden lines in the second spectrum makes identification insecure. Some mechanism must exist for loss of hydrogen from the position shown, since formaldehyde [22] and acetaldehyde [23] have been reported as oxidation products from dimethylamine and diethylamine. Spectra attributed to $\dot{\mathrm{C}} \mathrm{H}_{2} \mathrm{NH}_{3}^{+}$ $[24,25]$ have been observed in irradiated methylamine salts. A related species $\dot{\mathrm{C}} \mathrm{H}_{2} \mathrm{NH}_{2}^{+} \mathrm{CH}_{3}$ is unlikely in this instance, since it would require narrowly spaced (4 G) outer triplets.

The two amides investigated, $N$-dimethyl formamide, figure 9 and $N$-dimethylacetamide, figure 10 , table 4 , behaved differently, giving radical spectra in acid solution consisting of three groups of many lines. No serious attempt was made to understand the spectra. If the group intensities are really $1: 2: 1$, a formulation similar to Kohin's [24, 25] may be correct here: $\dot{\mathrm{C}} \mathrm{H}_{2} \mathrm{~N}\left(\mathrm{CH}_{3}\right)(\mathrm{COR})$, with all but the $\alpha$ splittings minor.

\subsection{Polyethylene Oxide and Other Ethers}

$$
\text { a. Introduction }
$$

Polyethylene oxide, figure 11 , table 5 , presented a spectrum of five groups of triplets, quintet spacing 8.7 $\mathrm{G}$, triplet spacing $1.9 \mathrm{G}$, with $g=2.00314$, plus variable amounts of another spectrum, a 1:2:1 triplet $(22.2 \mathrm{G})$ of doublets $(18.7 \mathrm{G}), g=2.0024$. The main spectrum has some features suggesting that of a radical-ion $m \sim \mathrm{O}-\mathrm{CH}_{2}^{+} \mathrm{CH}_{2} \mathrm{O} m$ or $m \mathrm{CH}_{2}^{+} \mathrm{OCH}_{2} m$, but we now believe it is that of the radical $m \mathrm{OCHCH}_{2} \mathrm{O} m$, with $a_{\beta}=\frac{1}{2} a_{\alpha}$. The evidence depends heavily upon the spectra from related glycol ethers to be discussed in the next section.

TABLE 4. Radicals from amides

\begin{tabular}{c|c|c|c|c|c}
\hline Substrate & $\begin{array}{c}\text { Triplet } \\
\text { separation, } \\
\mathrm{G}\end{array}$ & $\begin{array}{c}\text { Group } \\
\text { width, } \\
\mathrm{G}\end{array}$ & $\begin{array}{c}\text { Intragroup } \\
\text { separation, } \\
\mathrm{G}\end{array}$ & $\begin{array}{c}\text { Multi- } \\
\text { plicity }\end{array}$ & $g$ \\
\hline N-Dimethylformamide & $17.3 \pm 0.2$ & 10 & $1.2-3.8$ & $7-11$ & $2.0026 \pm 0.0010$ \\
N-Dimethylacetamide & $18.0 \pm 0.3$ & $10-15$ & 1.4 & $8-10$ & $2.0034 \pm 0.0003$ \\
\hline
\end{tabular}


b. Glycol Ethers

The glycol ethers, $Y-\left(\mathrm{OCH}_{2} \mathrm{CH}_{2}\right)_{-} \mathrm{OZ}$, where $Y$ and $Z$ are alkyl groups or hydrogen, gave complex spectra, figures 13 to 17 , tables 5 and 6 , which could be analyzed in terms of three types of radical spectra: I, $Y^{\prime} \dot{\mathrm{C}} \mathrm{HOCH}_{2} \mathrm{CH}_{2}$ m, derived by abstraction from a terminal alkyl group, with a $g$-value near 2.0032 and $a_{\alpha}, a_{\beta}$ and $a_{\gamma_{0}}$ "normal" for an aliphatic ether radical (cf. ref. 3, 4 and table 7). II, $\mathrm{Y}^{\prime} \mathrm{CH}_{2} \mathrm{OC}^{\circ} \mathrm{HCH}_{2} \mathrm{O}$ m and $m \mathrm{CH}_{2} \mathrm{OC} \mathrm{HCH}_{2} \mathrm{O} m$, derived by abstraction of an interior hydrogen; $g$ near $2.0032, a_{\alpha}$ near $17 \mathrm{G}, a_{\beta}$ near 9, $a_{\gamma_{0}}$ near 1 or $2 \mathrm{G}$. The low $a_{\beta}$ is like that found by Livingston and Zeldes in the radical $\dot{\mathrm{C}} \mathrm{HOHCH} \mathrm{H}_{2} \mathrm{OH}$ from ethylene glycol [9]; the reason for so low an $a_{\beta}$ is still unexplained. III, a radical of debatable structure, perhaps $\dot{\mathrm{C}} \mathrm{HOHCH} \mathrm{H}_{2} \mathrm{OZ}$, formed by abstraction

TABLE 5. Radicals from glycol ethers

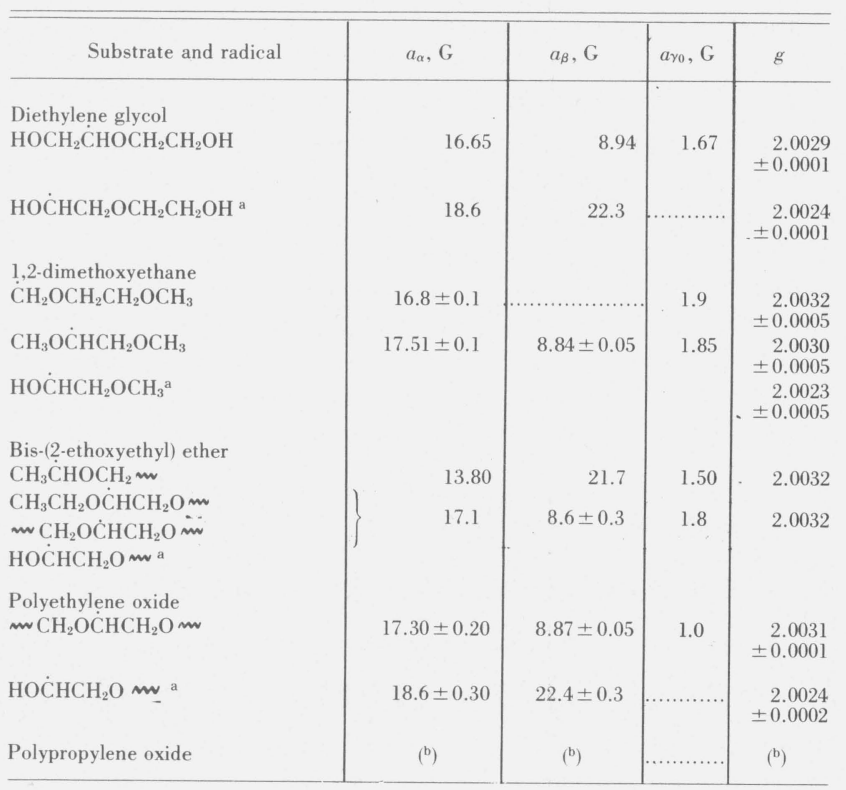

a Structure doubtful in view of $g$-value; parameters in line 2 ; see text. ${ }^{b}$ See text.

TABLE 6. Radicals from glycol ethers, supplementary

\begin{tabular}{|c|c|c|}
\hline Substrate & $\begin{array}{l}\text { Radicals with some } \\
\text { lines isolated }\end{array}$ & $\begin{array}{l}\text { Radicals with all } \\
\text { lines overlapped }\end{array}$ \\
\hline $\begin{array}{l}\mathrm{CH}_{3} \mathrm{OCH}_{2} \mathrm{CH}_{2} \mathrm{OH} \\
\mathrm{CH}_{3}\left(\mathrm{OCH}_{2} \mathrm{CH}_{2}\right)_{4} \mathrm{OCH}_{3}\end{array}$ & $\left\{\begin{array}{l}\text { II } \mathrm{CH}_{3} \mathrm{OC} \dot{\mathrm{C}} \mathrm{HCH}_{2} \mathrm{OH} \\
\text { and } m \sim \mathrm{CH}_{2} \mathrm{OC} \mathrm{HCH}_{2} \mathrm{Om} \\
\mathrm{III} \mathrm{HOCHCH}_{2} \mathrm{O} m\end{array}\right.$ & I $\dot{\mathrm{C}} \mathrm{H}_{2} \mathrm{OCH}_{2} \mathrm{CH}_{2} \mathrm{OH}$ \\
\hline $\begin{array}{l}\mathrm{C}_{2} \mathrm{H}_{5} \mathrm{OCH}_{2} \mathrm{CH}_{2} \mathrm{OH} \\
\mathrm{C}_{2} \mathrm{H}_{5}\left(\mathrm{OCH}_{2} \mathrm{CH}_{2}\right)_{2} \mathrm{OH}\end{array}$ & $\left\{\begin{array}{l}\mathrm{I} \mathrm{CH}_{3} \dot{\mathrm{C}} \mathrm{HOCH}_{2} \mathbf{m} \\
\text { (outer lines) } \\
\mathrm{III} \mathrm{HOC}^{\circ} \mathrm{HCH}_{2} \mathrm{Om}\end{array}\right.$ & $\begin{array}{l}\text { II (except small } \\
\text { center region) } \\
m \mathrm{CH}_{2} \mathrm{O} \dot{\mathrm{C}} \mathrm{HCH}_{2} \mathrm{O} m\end{array}$ \\
\hline $\begin{array}{l}\mathrm{C}_{4} \mathrm{H}_{9} \mathrm{OCH}_{2} \mathrm{CH}_{2} \mathrm{OH} \\
\mathrm{C}_{4} \mathrm{H}_{9}\left(\mathrm{OCH}_{2} \mathrm{CH}_{2}\right)_{2} \mathrm{OH}\end{array}$ & $\left\{\begin{array}{l}\text { III } \mathrm{HOC} \dot{\mathrm{C}} \mathrm{HCH}_{2} \mathrm{Om} \\
\text { I (non- } \alpha, \\
\mathrm{CH}_{3} \mathrm{CH}_{2} \dot{\mathrm{C}} \mathrm{HCH}_{2} \mathrm{Om} \text {, etc.) }\end{array}\right.$ & $\begin{array}{l}\text { II m } \mathrm{CH}_{2} \mathrm{O} \dot{\mathrm{C}} \mathrm{HCH}_{2} \mathrm{O} \\
\text { I }(\alpha \text {-type, } \\
\left.\mathrm{CH}_{3} \mathrm{CH}_{2} \mathrm{CH}_{2} \dot{\mathrm{C}} \mathrm{HOCH}_{2} \sim v\right)\end{array}$ \\
\hline
\end{tabular}

or subsequent hydrolysis, usually a minor product unless the parent compound has free hydroxyl groups. The $g$-value is $2.0024, a$ (doublet) $=18.7 \mathrm{G}, a$ (triplet) $=22.2 \mathrm{G}$. Objections to the proposed formula are the low $g$-value, and the high $a_{\beta}$, which disagree with $g=2.00308, a_{\beta}=9.94 \mathrm{G}$ for $\dot{\mathrm{CHOHCH}}_{2} \mathrm{OH}$ [9]. Diethylene glycol according to this scheme can form only two radicals: $\mathrm{HOCH}_{2} \mathrm{CH}_{2} \mathrm{OC} \mathrm{HCH}_{2} \mathrm{OH}$ (type II) and $\mathrm{HOCH}_{2} \mathrm{CH}_{2} \mathrm{OCH}_{2} \dot{\mathrm{C}} \mathrm{HOH}$ (type III). Figure 13 and the entry in table 5 seem unequivocal, with all lines either resolved or clearly present as anomalies in intensity or form. In dimethoxyethane, figure 14, enough lines are resolved to support the entries in table 5 for the type II radical $\mathrm{CH}_{3} \mathrm{O} \dot{\mathrm{C}} \mathrm{HCH}_{2} \mathrm{OCH}_{3}$, as well as the type I radical $\dot{\mathrm{C}} \mathrm{H}_{2} \mathrm{OCH}_{2} \mathrm{CH}_{2} \mathrm{OCH}_{3}$ previously described [3]. The contribution from type III is unusually weak. In both of the type II radicals, there is a close but incomplete approach to $a_{\beta}=\frac{1}{2} a_{\alpha}$. In bis(2-ethoxyethyl)ether, figure 15, the overlap is more confused and it is impossible to distinguish the two possible type II radicals, $\mathrm{CH}_{3} \mathrm{CH}_{2} \mathrm{O} \dot{\mathrm{C}} \mathrm{HCH}_{2} \mathrm{O} m$ and $\mathrm{CH}_{3} \mathrm{CH}_{2} \mathrm{OCH}_{2} \dot{\mathrm{C}} \mathrm{HO} m$. From cursory inspection of regions free from overlap, and of relative intensities where overlap is nearly perfect, other glycol ethers show similar behavior, figure 16, table 6. Spectra from the two butyl ethers were very poor, with extreme loss of intensity at low field. The presence of lines as far as $70 \mathrm{G}$ from the center of the spectrum indicates that some attack is occurring on the terminal butyl groups at positions other than the functional group.

TABLE 7. Radicals from ethers and acetals

\begin{tabular}{|c|c|c|c|c|}
\hline Radical and substrate & $a_{\alpha}, \mathrm{G} \cdot$ & $a_{\beta}, \mathrm{G}$ & $a_{\gamma_{0}}, \mathrm{G}$ & $g$ \\
\hline Dimethyl ether $\cdot \mathrm{CH}_{2} \mathrm{OCH}_{3}$ & $16.7 \pm 1$ & & $1.8 \pm 0.1$ & \\
\hline $\begin{array}{l}\text { Diethyl ether } \\
\mathrm{CH}_{3} \mathrm{CHOCH} \mathrm{CH}_{3}{ }^{\mathrm{a}}\end{array}$ & 13.8 & 22.2 & 1.30 & $\begin{array}{r}2.0032 \\
\pm 0.0010\end{array}$ \\
\hline$\cdot \mathrm{CH}_{2} \mathrm{CH}_{2} \mathrm{OCH}_{2} \mathrm{CH}_{3}{ }^{\mathrm{c}}$ & 22.0 & 28.3 & & $\begin{array}{r}2.0026 \\
\pm 0.0010\end{array}$ \\
\hline $\begin{array}{l}\text { Tetrahydrofuran } \\
\dot{\mathrm{C}} \mathrm{HCH}_{2} \mathrm{CH}_{2} \mathrm{CH}_{2} \mathrm{O}\end{array}$ & & & & $\begin{array}{r}2.0031 \\
\pm 0.0004\end{array}$ \\
\hline $\mathrm{CH}_{2} \dot{\mathrm{C}} \mathrm{HCH}_{2} \mathrm{CH}_{2} \mathrm{O}$ & $21.2 \pm 0.5$ & $35.6 \pm 0.5$ & & $\begin{array}{r}2.0025 \\
\pm 0.0004\end{array}$ \\
\hline $\begin{array}{l}\text { Vinyl ethyl ether } \\
\cdot \mathrm{CH}_{2} \mathrm{CH}(\mathrm{OH})\left(\mathrm{OC}_{2} \mathrm{H}_{5}\right)\end{array}$ & $22.7 \pm 0.2$ & $18.8 \pm 0.2$ & & $\begin{array}{r}2.0025 \\
\pm 0.0001\end{array}$ \\
\hline $\mathrm{HOCH}_{2} \dot{\mathrm{C}} \mathrm{HOC}_{2} \mathrm{H}_{5}{ }^{\mathrm{c}}$ & 17.3 & 8.9 & 1.6 & $\begin{array}{r}2.0029 \\
\pm 0.0001\end{array}$ \\
\hline Methylal $\cdot \mathrm{CH}_{2} \mathrm{OCH}_{2} \mathrm{OCH}_{3}$ & $17.0 \pm 0.1$ & & $0.78 \pm 0.03$ & $\begin{array}{r}2.0032 \\
\pm 0.0001\end{array}$ \\
\hline $\mathrm{CH}_{3} \mathrm{OC} \mathrm{COCH}_{3}$ & $13.0 \pm 0.1$ & & $0.75 \pm 0.05$ & $\begin{array}{r}2.0031 \\
\pm 0.0001\end{array}$ \\
\hline $\begin{array}{l}\text { Paraldehyde } \\
\mathrm{CH}_{3} \dot{\mathrm{C}}\left[\mathrm{OCH}\left(\mathrm{CH}_{3}\right)\right]_{2} \mathrm{O}\end{array}$ & & $14.48 \pm 0.10$ & & $\begin{array}{r}2.0030 \\
\pm 0.0010\end{array}$ \\
\hline
\end{tabular}




\section{c. Structure of the Polyethylene Oxide Radical}

From the spectra of the glycol ethers it becomes plausible that the quintet of triplets from polyethylene oxide is accidental-that the structure is $m \mathrm{CH}_{2} \mathrm{O}$ $\dot{\mathrm{C}} \mathrm{HCH}_{2} \mathrm{OCH}_{2}$ m, and that the partial overlap of centerlines seen in $\dot{\mathrm{C}} \mathrm{HOHCH}{ }_{2} \mathrm{OH}, \mathrm{CH}_{2} \mathrm{OHC} \dot{\mathrm{C}} \mathrm{HOCH}_{2} \mathrm{CH}_{2}$ $\mathrm{OH}$ and $\mathrm{CH}_{3} \mathrm{OC} \dot{\mathrm{C}} \mathrm{HCH}_{2} \mathrm{OCH}_{3}$ becomes a nearly perfect coincidence in the polymer radical. At $25{ }^{\circ} \mathrm{C}$ the best values of parameters are $g=2.0031 \pm .0001, a_{\alpha}=17.30$ $\pm 0.1 \mathrm{G}, a_{\beta}=8.87 \pm 0.05 \mathrm{G}$. At $40{ }^{\circ} \mathrm{C}$, figure 12 (with peroxide concentration reduced to $0.025 M$ to slow up the overall reaction and observe high concentration) the ratio $a_{\beta} / a_{\alpha}$ has risen from 0.513 to 0.533 . This slight shift and less perfect coincidence greatly diminish the apparent intensity of the centerlines. Differences in apparent linewidth are hardly perceptible; the average width is slightly greater for a centerline, especially at $40^{\circ} \mathrm{C}$. The relative intensity of a centerline was greatest at $5{ }^{\circ} \mathrm{C}$ and also in the presence of magnesium sulfate at room temperature.

The relative intensity of the minor, type III, spectrum was greatest with material of low molecular weight $(400)$ and least with high molecular weight $(20,000)$ and at $5{ }^{\circ} \mathrm{C}$. It is conceivable that type II radicals can undergo hydrolytic conversion to type III. As minor evidence that the quintet of triplets is not due to a radical-ion, it was noted that intensity of this spectrum was not greatly affected by changes in ionic strength and that some of this spectrum (and none of type III) persisted when the mixture $p \mathrm{H}$ was changed to 8.0 , by additions of carbonate and bicarbonate to the peroxide reagent. For a radical ion, disappearance should have been accelerated at high ionic strength,

$$
\mathrm{R}^{+}+\mathrm{R}^{+} \rightarrow \text { product }
$$

and conversion could have been expected at higher $p \mathrm{H}$,

$$
m \sim \mathrm{CH}_{2} \mathrm{CH}_{2}{ }^{+} \dot{\mathrm{O} C H} \mathrm{H}_{2} \sim v \rightarrow \mathrm{H}^{+}+m \sim \mathrm{CH}_{2} \dot{\mathrm{C}} \mathrm{HOCH}_{2} m
$$

d. Miscellaneous Ethers and Acetals

Dimethyl ether and diethyl ether [3] are included in table 7 merely for comparison of parameters obtained in this laboratory; the slight differences from the literature are not necessarily significant. In diethyl ether, a small centerline seems to be associated with two others at $\pm 22.0 \mathrm{G}$ and feeble end lines at $\pm 50.3 \mathrm{G}$ from it. If these are among the strong lines and end lines of the radical $\cdot \mathrm{CH}_{2} \mathrm{CH}_{2} \mathrm{OCH}_{2} \mathrm{CH}_{3}$, then one can deduce, $a_{\alpha}+a_{\beta}=50.3 \mathrm{G}, a_{\alpha}\left(\right.$ or $\left.a_{\beta}\right)=22.0 \mathrm{G}, a_{\beta}$ (or $\left.a_{\alpha}\right)=28.3 \mathrm{G}, g=2.0026 \pm 0.0010$ (uncorrected), relying on the analysis of Livingston and Zeldes [9] for $\mathrm{CH}_{2-}$ $\mathrm{CH}_{2} \mathrm{OH}$.

Tetrahydrofuran, figure 17, table 7 , exhibited in

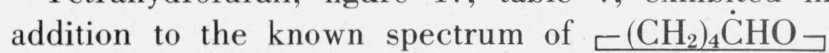
[14] a second spectrum of lower $g$, reasonably attributed to $\sqsubset\left(\mathrm{CH}_{2}\right)_{2} \dot{\mathrm{C}} \mathrm{HCH}_{2} \mathrm{O} \sqsupset$. The $a_{\beta}$ is large, as expected from molecular models and the $\cos ^{2} \theta$ variation.
The magnitude of $a_{\beta}$ is expected to be approximately proportional to $\cos ^{2} \theta[4,32]$ where $\theta$ is the angle between the $p$-orbit axis and the projection of the $\beta \mathrm{C}-\mathrm{H}$ bond upon a plane perpendicular to the $\mathrm{C}_{\alpha}-\mathrm{C}_{\beta}$ bond. The small $a_{\gamma}$ is not resolved but contributes to line broadening. Resolution might be difficilt under the most favorable conditions, as the four $\beta$ protons may not be quite equivalent, and the second-order splitting should be unusually large [16]. Chlorination products analogous to both radicals have been observed [26].

Vinyl ethyl ether, figure 18 , table 7 , by analogy with Fischer's cases [8] should give $\mathrm{HOCH}_{2} \dot{\mathrm{C}} \mathrm{HOC}_{2} \mathrm{H}_{5}$ by addition. The spectrum should be similar to those of the type II radicals in glycol ethers and identical to one of the spectra from $\mathrm{C}_{2} \mathrm{H}_{5} \mathrm{OCH}_{2} \mathrm{CH}_{2} \mathrm{OH}$, figure 16 , much of which, however, is obscured by other lines. This spectrum can perhaps be associated with the weak triplet lines in figure 18, but the lines are too weak for secure identification.

The principal spectrum of low $g$ and no $\gamma$-splittings is best explained by addition in the reverse direction, $\mathrm{OH}$

$\dot{\mathrm{C}} \mathrm{H}_{2} \mathrm{CH}-\mathrm{OC}_{2} \mathrm{H}_{5}$. It is uncertain whether any radicals resulting from abstraction are present here, e.g., $\mathrm{CH}_{3} \dot{\mathrm{C}} \mathrm{HOCH}=\mathrm{CH}_{2}$. Either abstraction or reverse addition may be involved in the usual difficulty of free-radical polymerization. In 1,1-dialkoxy derivatives, abstraction occurs from the 1-position of both the alkyl group and the methylene (or substituted methylene) bridge, but less readily than in simple ethers. For example, methylal gave both $\dot{\mathrm{C}} \mathrm{H}_{2} \mathrm{OCH}_{2} \mathrm{OCH}_{3}$ and $\dot{\mathrm{C}} \mathrm{H}\left(\mathrm{OCH}_{3}\right)_{2}$, of expected spectral structure indicated in figure 19 and table 7 . The $g$-value of $\dot{\mathrm{C}} \mathrm{H}\left(\mathrm{OCH}_{3}\right)_{2}$ is within .00006 units of that of $\dot{\mathrm{C}} \mathrm{H}_{2} \mathrm{OCH}_{2} \mathrm{OCH}_{3}$. The spectrum of $\dot{\mathrm{C}} \mathrm{H}\left(\mathrm{OCH}_{3}\right)_{2}$ requires a $\gamma 0$-splitting into seven components of which five are clearly visible at low modulation, figure 19 , in fair correspondence with the expected intensity-ratios, (1)-6-15-20-15-6-(1). Paraldehyde, figure 20 , table 7 , gave a quartet with a $14.5 \mathrm{G}$ splitting, but no further small splitting was visible, although the peak width was only $0.38 \mathrm{G}$. The radical is nevertheless most probably $\mathrm{CH}_{3}-\dot{\mathrm{C}}-\mathrm{OCH}-\mathrm{OCH}-\mathrm{O}-$ despite the absence of the expected $\gamma 0$ splitting. It is certainly not $\mathrm{CH}_{3} \dot{\mathrm{C}}(\mathrm{OH})_{2}$, for which a repetition of the original work of Buley and Norman [6] confirmed the reported $22 \mathrm{G}$ splitting, see also table 9. The $g$-value of the latter is about $2.0026 \pm 0.0002$. Unless the paraldehyde concentration was high, the hydroxyl peak was also present. Experiments with trioxymethylene produced no radical spectrum other than hydroxyl.

\section{e. Polypropylene Oxide}

Unlike polyethylene oxide, polypropylene oxide produced no clear radical spectra other than that of the parent glycol $\mathrm{CH}_{3} \mathrm{CHOHCH}_{2} \mathrm{OH}$, discussed in a 
later section. Large quantities of the glycol may have been present in the commercial sample, although an attempt was made to remove glycols by repeated extraction with aqueous magnesium sulfate. If the samples were glycol-free, the result indicates that this polyether, unlike polyethylene oxide, is subject to the same complex reactions as glycols themselves.

\subsection{Glycols and Vicinal Polyhydroxy Compounds}

The complex ESR spectra from simple and polymeric carbohydrates, figure 28 , are unlikely to be understood without reliable knowledge of simpler polyhydroxy compounds. The treatment here remains preliminary and tentative.

\section{a. Ethylene and Propylene Glycol}

For ethylene glycol, the literature contains two irreconcilable spectra. In a titanous-peroxide system, Dixon and Norman [2] obtain a 1:2:1 triplet which they tentatively ascribe to $\cdot \mathrm{CH}_{2} \mathrm{OH}$ derived from scission of $\dot{\mathrm{C}} \mathrm{HOHCH} \mathrm{H}_{2} \mathrm{OH}$. In photolyzed peroxide solution, Zeldes and Livingston [9] obtain a complex overlapping set of lines which satisfies with high precision the assignment $-\dot{\mathrm{C}} \mathrm{HOHCH}_{2} \mathrm{OH}, g=2.00308$, $a_{\alpha}=17.54 \mathrm{G}, a_{\beta}=9.94 \mathrm{G}, a_{\mathrm{H}(\mathrm{OH})}=1.044 \mathrm{G}$ and $0.316 \mathrm{G}$. Our experiments reveal two radical spectra, figure 21 , table 8 . The minor spectrum is relatively more prominent under nearly neutral conditions obtained by the addition of borax plus sulfuric acid to both reagent solutions, or by the omission of sulfuric acid from the titanium solution. The origin of the minor spectrum is uncertain; although its lines and $g$-value would be compatible with the assignment $\mathrm{CH}_{2} \mathrm{OHC} \mathrm{CHOH}$, the splitting parameters differ grossly from those of Livingston and Zeldes. The major triplet spectrum has $g=2.0046$, and is not identical to that of $\dot{\mathrm{C}} \mathrm{H}_{2} \mathrm{OH}$ derived from methanol. In mixtures of methanol and glycol, the two spectra are distinct, figure 21. Propylene

TABLE 8. Radicals from vicinal polyhydroxyl compounds

\begin{tabular}{|c|c|c|c|c|c|c|}
\hline Substrate and radical & $a_{\alpha}, \mathrm{G}$ & $a_{\beta}, \mathrm{G}$ & $a_{m}, \mathrm{G}$ & $a_{\beta m}, \mathrm{G}$ & $g$ & Other \\
\hline $\begin{array}{l}\text { Ethylene glycol } \\
\cdot \mathrm{CH}_{2} \mathrm{CH}=\mathrm{O}\end{array}$ & $\begin{array}{r}19.1 \\
+0.2\end{array}$ & & $<2$ & & 2.0046 & Width, $2.2 \mathrm{G}$ \\
\hline $\mathrm{HOC} \mathrm{HCH}_{2} \mathrm{OH}^{\text {a }}$ & $\begin{array}{l} \pm 0.2 \\
15.8\end{array}$ & 21.1 & & & 2.0034 & \\
\hline $\begin{array}{l}\text { Propylene glycol } \\
\cdot \mathrm{CH}_{2} \mathrm{COCH}_{3}\end{array}$ & 19.71 & & & $\begin{array}{r}0.93 \\
+.03\end{array}$ & 2.0044 & \\
\hline $\begin{array}{l}\text { Glycerol } \\
\cdot \mathrm{CH}_{2} \mathrm{COCH} \mathrm{CH}_{2} \mathrm{OH}\end{array}$ & 19.2 & & & 2.2 & 2.0041 & \\
\hline $\mathrm{HOCH}_{2} \mathrm{CHCH}=\mathrm{O}$ & 18.0 & 24.9 & 1.4 & & $\begin{array}{r}2.0041 \\
\pm 0.0002\end{array}$ & \\
\hline $\begin{array}{l}\text { Mannitol } \\
\text { (see text) }\end{array}$ & & & & & & \\
\hline $\begin{array}{l}\text { Inositol } \\
\text { - } \mathrm{CHOHC}(\mathrm{OH}) \mathrm{CHOH}-\end{array}$ & & & & & & \\
\hline$-\mathrm{CHOHC}(\mathrm{OH}) \mathrm{CHOH}-$ & & $\begin{array}{r}30.5 \\
\pm 1.0\end{array}$ & & & $\begin{array}{r}2.0034 \\
\pm 0.0010\end{array}$ & \\
\hline$-\mathrm{CHOHCHCOCHOH}$ & $\begin{array}{r}17.5 \\
\pm 1.0\end{array}$ & $\begin{array}{r}37.5 \\
\pm 1.0\end{array}$ & & $\begin{array}{r}2.7 \\
\pm 0.5\end{array}$ & $\begin{array}{r}2.0041 \\
\pm 0.0010\end{array}$ & \\
\hline
\end{tabular}

adentity not established. glycol yielded a confused sharp-lined spectrum of high $g$, figure 22 , table 8 , in which many of the lines coincided with those given by acetone $[3,27]$. It is proposed that the radical from propylene glycol is $\mathrm{CH}_{2} \mathrm{COCH}_{3}$, and that by analogy, the triplet spectrum from ethylene glycol belongs to the radical $\dot{\mathrm{C}} \mathrm{H}_{2} \mathrm{CHO}$. Similar arguments have appeared recently [28, 29]. Although a molecular orbital account will not be attempted, allylic resonance structures can be written for these radicals,<smiles>CC/C=C\OCC=C(C)[O-]</smiles>

The consequence of this resonance forrmulation would be a low spin density upon the middle member (carbonyl carbon) and appreciable spin density upon oxygen. The latter accounts for the high $g$-value, the former for the observed low splitting due to $\mathrm{CH}_{3}$ in $\dot{\mathrm{C}} \mathrm{H}_{2} \mathrm{COCH}_{3}$ and for the presumed low splitting due to $\mathrm{CH}$ in $\dot{\mathrm{C}} \mathrm{H}_{2} \mathrm{CHO}$, table 8 . As a mechanism for formation of these radicals, it is proposed that, in acid solution, the initially formed radical very rapidly loses a hydroxyl ion from the beta position and a hydrogen ion from the alpha position,

$$
\begin{aligned}
& \mathrm{CH}_{2} \mathrm{OH} \dot{\mathrm{C}} \mathrm{HOH} \stackrel{\mathrm{H}^{+}}{\rightarrow}\left[\stackrel{+}{\mathrm{C}} \mathrm{H}_{2}-\dot{\mathrm{C}} \mathrm{H}-\mathrm{OH}\right]+\mathrm{OH}^{-} \\
& \rightarrow\left[\mathrm{CH}_{2}-\dot{\mathrm{C}} \mathrm{H}-\overline{\mathrm{O}}-\right] \mathrm{H}^{+} \rightarrow \dot{\mathrm{C}} \mathrm{H}_{2} \mathrm{CH}=\mathrm{O} .
\end{aligned}
$$

The steps may be concerted, and the net result is indistinguishable from the internal electron transfer proposed to explain the radical obtained from chloral [3],

$$
\mathrm{CCl}_{3} \dot{\mathrm{C}}(\mathrm{OH})_{2} \rightarrow \dot{\mathrm{C}} \mathrm{Cl}_{2} \mathrm{CO}_{2} \mathrm{H}+\mathrm{H}^{+}+\mathrm{Cl}^{-} \text {. }
$$

The presence of water alone is not sufficient [9] to give the triplet spectrum in ethylene glycol, which we associate with the proposed radical, therefore the necessity of acid is assumed. The spectra from photolyzed mixtures of propylene glycol and hydrogen peroxide have been examined [9] but not yet published in detail. If the present hypothesis is correct they will be quite different from the spectra found here.

The hypothesis presented here assumes that $g$ value is very strongly correlated with chemical character of the radical, i.e., the nature of atoms having high spin density, and is less sensitive to such influences as solvent and conformation of molecules. This view is so far supported by massive evidence only in two cases - the alkyl radicals [17] and the radicals $\mathrm{R} \dot{\mathrm{C}} \mathrm{HOH}$ [9], and may be subject to exception, if the radical $\mathrm{HOCH}_{2} \mathrm{CH}_{2} \mathrm{OCH}_{2} \dot{\mathrm{C}} \mathrm{HOH}$, discussed under diethylene glycol, has been correctly identified. 


\section{b. Glycerol and Mannitol}

The same hypothesis accounts satisfactorily enough for the spectra from glycerol, figure 23 , table 8 . Two spectra can be distinguished: I, a 1:2:1 triplet (19.2 G) of triplets $(2.2 \mathrm{G})$ and II, a 1:2:1 triplet $(24.9 \mathrm{G})$ of doublets (18.0 G) each split further into doublets (1.4 G). The $g$-values are again high, 2.0041; by observation of near coincidences they differ by a barely perceptible amount. Spectrum I is assigned to the radical<smiles>O=[Co]</smiles>

$\dot{\mathrm{C}} \mathrm{H}_{2} \mathrm{C}-\mathrm{CH}_{2} \mathrm{OH}$, with the $19.2 \mathrm{G}$ splitting due to $\begin{array}{lll}1 & 2 & 3\end{array}$

protons on position 1 and the $2.2 \mathrm{G}$ splitting to those on 3 . Position 3 is $\beta$ to a midposition of low spin density in a pseudoallylic radical. Spectrum II is assigned to radical $\mathrm{HOCH}_{2} \dot{\mathrm{C}} \mathrm{HCHO}$, where $a_{1}=24.9 \mathrm{G}, a_{2}=18.0$ (1) (2) (3)

$\mathrm{G}$, and $a_{3}=1.4 \mathrm{G}$. In the allylic formulation, position 2 is a position of high spin density, 1 is $\beta$ with respect to a position of high spin density, and 3 is a middle position of low spin density. Alternative views can be entertained, if one abandons a close association of $g$-value with chemical type; according to such views these spectra might be attributed to $\mathrm{CH}_{2} \mathrm{OHCHO}$ $\mathrm{HCHOH}[29 \mathrm{a}]$, to smaller radicals arising from scission, or might contain lines hidden and broadened by oscillations at intermediate frequencies as in dioxane [4]. Against the idea of extensive scission is the observation that dihydroxyacetone and glyceraldehyde are often important products of oxidation with Fenton's reagent [30].

Unlike the spectrum from ethylene glycol, the spectra from glycerol and propylene glycol at low acidity were diminished in intensity but unchanged in nature, an observation which tends to weaken the present hypothesis of a special acid mechanism of attack. The radical $\mathrm{HOCH}_{2} \dot{\mathrm{C}} \mathrm{HCHO}$, associated with glycerol spectrum II, is a possible product from addition of hydroxyl to acrolein. Lines of this radical seem to exist in the weak, complex experimental spectrum to be discussed later, figure 28 .

Mannitol, figure 24, shows accumulation of lines in about the same regions as glycerol, but with low intensity in the regions for spectrum II. This can be accommodated to the "acid" mechanism in a loose statistical way by noting that initial attack in most positions ultimately yields radicals having either two $\alpha$, two $\beta$ or one $\alpha$ and $1 \beta$ proton, with respect to a position of high spin density, while only attack at

positions 3 and 4 can form $\mathrm{CH}_{2} \mathrm{OHC} \mathrm{CHCCHOH} m$, with a probability of $1 / 2$ in each case because of the two possible sites for loss of $\mathrm{OH}^{-}$. Given the roughly equal values of splitting parameters, most lines will be in the region of spectrum $I$ and a few in the region of spectrum II. Further analysis would require very reliable measurement of line positions and improved resolution. The suggested presence of $\mathrm{CH}_{2} \mathrm{OH}$ [29a] is untenable, as discussed under ethylene glycol. c. Inositol

The spectra from inositol, meso- or myo-inositol, figure 25 , table 8 , seem to show that the proposed acid mechanism of attack is not followed exclusively. The stronger lines can be attributed to a superposition of two spectra: I, $g=2.0034$; two equivalent protons, $a=30.5 \pm 1$ G. II, $g=2.0041$; three nonequivalent protons, $a=37.5 \pm 1,17.5 \pm 1,2.7 \pm 0.5 \mathrm{G}$. The differing $g$-values suggest two modes of attack-simple abstraction, and the "acid" mode of attack proposed for glycols.

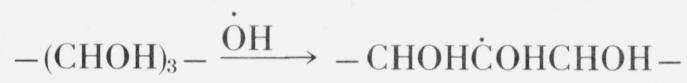

I

$$
\begin{array}{r}
-(\mathrm{CHOH})_{4}-\stackrel{\cdot \mathrm{OH}}{\longrightarrow} \\
-(\mathrm{CHOH})_{2} \dot{\mathrm{COHCHOH}}-\stackrel{\left(-\mathrm{OH}^{-},-\mathrm{H}^{+}\right)}{\longrightarrow} \\
-\mathrm{CHOH}-\dot{\mathrm{C}} \mathrm{H}-\mathrm{CO}-\mathrm{CHOH}-
\end{array}
$$

In $\mathrm{I}, a=30.5 \mathrm{G}$ is necessarily due to two $\beta$ hydrogens. In II, see resonance formula,

$$
\begin{aligned}
& \begin{array}{lllll}
1^{\prime} & 2^{\prime} & 3^{\prime} & 4^{\prime}
\end{array} \\
& -\mathrm{CHOH}-\dot{\mathrm{C}} \mathrm{HC}-\mathrm{CHOH}-\leftrightarrow
\end{aligned}
$$

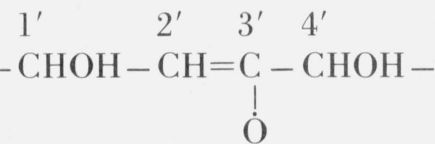

position $3^{\prime}$ corresponds to the midposition in an allyl radical, $2^{\prime}$ and 0 to the end-positions, $l^{\prime}$ is $\beta$ to an end-position, and $4^{\prime}$ is $\beta$ to the midposition. The $17.5 \mathrm{G}$ splitting is attributed to position $2^{\prime}$, the $37.5 \mathrm{G}$ splitting to $\mathrm{I}^{\prime}$, and the $2.7 \mathrm{G}$ splitting to $4^{\prime}$. In the structure of the parent molecule [31], all $\mathrm{H}$ but No. 2 are axial; the

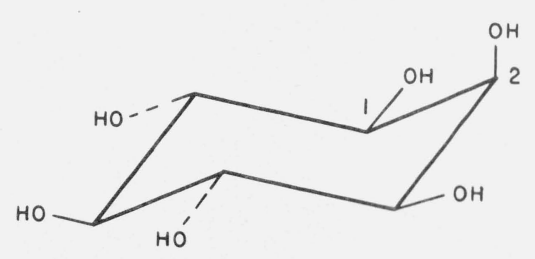

latter position is also the preferred site of microbiological oxidation. The structure and configuration 
of radicals I and II remain uncertain. Under the $\cos ^{2} \theta$ rule $[4,32]$, the $30.5 \mathrm{G}$ splitting of radical $\mathrm{I}$ is due to two highly axial $\beta$ protons. Abstraction from position 2 would satisfy this condition, but so would abstraction from any other position except 1 or 3 . It is assumed that the conformations are little changed by abstraction, as in dioxane [4], but also contrarily, that interconversion of chair forms is impossible or infrequent. Computation of $\theta$ seems futile for two reasons (1) we lack a reliable rotational-average $a_{\beta}$, as $\mathrm{CH}_{2} \mathrm{OH} \dot{\mathrm{C}} \mathrm{HOH}$ is anomalous, and (2) the $a_{\beta}$ in $\mathrm{CHOH}$ and $\mathrm{CH}_{2}$ groups seem to vary unaccountably, even when spin density and geometry are presumably held constant [5]. Molecular orbital reasons underlying the latter sort of variation have been suggested. In radicals of structure II, allylic resonance can deform the ring more severely than in I toward a cyclohexene structure. A very low $\theta$ is needed to account for the $37.5 \mathrm{G}$ splitting. Examination of models suggests, inconclusively, that with attack at 2 and $\mathrm{OH}$ loss from 1 or 3 , the $\beta$ positions 6 or 4 can be highly axial. The $2.7 \mathrm{G}$ splitting in II is in the low range expected for a position adjacent to an allylic midposition. Other possibilities not considered in detail for these radicals are ring opening - which does not always occur in oxidations [31] and which would probably require one splitting of 15 to $18 \mathrm{G}$ and one unknown in the radical-and the existence of broad, hidden peaks due to slow interconversions [4].

\subsection{Miscellaneous Carbonyl Compounds}

The spectra from acetaldehyde [6] and acetone $[3,27]$ have been discussed elsewhere.

Diacetone alcohol appears to give spectra of three theoretically anticipated radicals, figure 26, table 9 . The minor splittings of the radicals

$\dot{\mathrm{C}} \mathrm{H}_{2} \mathrm{C}\left(\mathrm{CH}_{3}\right)(\mathrm{OH}) \mathrm{CH}_{2} \mathrm{COCH}_{3}$ and $\mathrm{CH}_{2} \mathrm{CO} \dot{\mathrm{C}} \mathrm{HC}(\mathrm{OH})\left(\mathrm{CH}_{3}\right)_{2}$ must be of two kinds in view of the unequal intervals, but cannot be determined with certainty. Acrolein gave a weak, broadlined spectrum, unsatisfactory for interpretation, figure 27 , to which reference has been made above. Of the many possible reaction products,

\section{$\mathrm{HOCH}_{2} \dot{\mathrm{C}} \mathrm{HCHO}$}

formed by addition, seems to be present as a minor product when the acrolein concentration is low; cf. glycerol spectrum II. The radical $\mathrm{CH}_{2}=\mathrm{CH} \dot{\mathrm{C}} \mathrm{HOH}$, a possible electron transfer product, is excluded by comparison with $\mathrm{CH}_{2}=\mathrm{CHC} \mathrm{CHOH}$ from allyl alcohol [9]. Clogging of equipment by hard polymer was troublesome. A choice consistent with the exclusions mentioned is the growing polymer radical

$$
m \mathrm{CH}_{2} \dot{\mathrm{C}} \mathrm{HCH}=\mathrm{O} \text {, }
$$

table 9 , but it commands little confidence.

Ethyl acetate was attacked almost exclusively in the ethyl group to yield $\mathrm{CH}_{3} \dot{\mathrm{C}} \mathrm{HOCOCH}{ }_{3}$ (parameters in table 9). Comparison with the radical

\section{$\mathrm{HOCH}_{2} \dot{\mathrm{C}} \mathrm{HCOOCH}_{3}$}

[8] where the unpaired electron is in the carboxylic acid group, shows that both radicals have $g$-values in the range typical of acid and alcohol radicals rather than ketones, and that minor hyperfine interactions are transmitted across the carboxyl linkage, in both directions, about as effectively as across the ether linkage in $\dot{\mathrm{C}} \mathrm{H}_{2} \mathrm{OCH}_{3}$.

TABLE 9. Radicals from aldehydes and ketones

\begin{tabular}{|c|c|c|c|c|}
\hline Substrate and radical & $a_{\alpha}, \mathrm{G}$ & $a_{\beta}, \mathrm{G}$ & $g$ & Other \\
\hline $\begin{array}{l}\text { Acetone } \\
\cdot \mathrm{CH}_{2} \mathrm{COCH}_{3}{ }^{\mathrm{a}}\end{array}$ & $19.71 \pm 0.05$ & & $2.00410 \pm 0.00004$ & $a_{\mathrm{CH}_{3}}=0.93 \pm 0.03 \mathrm{G}$ \\
\hline $\begin{array}{l}\text { Diacetone alcohol } \\
\cdot \mathrm{CH}_{2} \mathrm{C}\left(\mathrm{CH}_{3}\right)(\mathrm{OH}) \mathrm{CH}_{2} \mathrm{COCH}_{3} \\
\cdot \mathrm{CH}_{2} \mathrm{COCH}{ }_{2} \mathrm{C}(\mathrm{OH})\left(\mathrm{CH}_{3}\right)_{2} \\
\mathrm{CH}_{3} \mathrm{COCHC}(\mathrm{OH})\left(\mathrm{CH}_{3}\right)_{2}\end{array}$ & $\begin{array}{l}21.9 \\
18.8 \\
18.7\end{array}$ & & $\begin{array}{l}2.0022 \pm 0.0010 \\
2.0042 \pm 0.0010 \\
2.0042\end{array}$ & $\begin{array}{l}a \gamma_{\mathrm{CH}_{3}} \neq a \gamma_{\mathrm{CH}_{2}} \cong 0.9 \mathrm{G} . \\
a \gamma_{\mathrm{CH}_{2}} \text { unresolved. } \\
a \gamma_{\mathrm{COCH}_{3}} \neq a \gamma_{\mathrm{CH}_{3}} \cong 0.9 .\end{array}$ \\
\hline $\begin{array}{l}\text { Acetaldehyde } \\
\mathrm{CH}_{3} \dot{\mathrm{C}}(\mathrm{OH})_{2}{ }^{\mathrm{b}}\end{array}$ & & $22.5 \pm 0.5$ & $2.0026 \pm 0.0002$ & \\
\hline $\begin{array}{l}\text { Acrolein } \\
m \mathrm{CH}_{2} \dot{\mathrm{C}} \mathrm{HCHO}^{\mathrm{c}}\end{array}$ & $19 \pm 1$ & $2 \mathrm{l} \pm 1 \mathrm{CH}_{2}$ & $2.0042 \pm 0.0002$ & \\
\hline Ethylacetate & & & & \\
\hline $\mathrm{CH}_{3} \dot{\mathrm{C}} \mathrm{HOCOCH}$ & 18.7 & 23.8 & 2.0035 & $a_{\mathrm{OCOCH}}^{\mathrm{H}}=1.4 \mathrm{G}$. \\
\hline $\begin{array}{l}\text { Methyl acrylate }{ }^{d} \\
\mathrm{HOCH}_{2} \dot{\mathrm{C}} \mathrm{HCOOCH}\end{array}$ & 20.19 & 26.62 & 2.0032 & $a_{\mathrm{COOCH}_{3}}^{\mathrm{H}}=1.14 \mathrm{G}$. \\
\hline
\end{tabular}




\subsection{Carbohydrate Polymers}

Although a number of mono- and disaccharides were investigated it is premature to attempt interpretation of spectra. The complexity suggests that very accurate knowledge of fields, as from simultaneous microwave and proton frequency counters, will be necessary for secure identification. The overall lack of symmetry, figure 28 , indicates the presence of radicals of several $g$-values, as though both simple abstraction and the proposed acid mechanism were involved. Presumably the latter could be repressed by photolytic generation. From the simplicity of products of chemical oxidation under some conditions [31], one can anticipate that ring opening and scission need not be important processes at short times. Individual radical spectra could be simple since appreciable hyperfine interaction cannot usually be expected from more than two protons, in general of unequal splitting constants, leading to four lines of equal intensity. The spectrum from glucose, figure $28 \mathrm{~b}$, is one of the most complex, perhaps because the solution contains large amounts of material in both $\alpha$ and $\beta$ configurations. In dextran [10], figure $28 \mathrm{a}$, the four prominent lines, if they belong to one radical, indicate a $g$-value of 2.0044. Soluble starch and corn dextrin, figures $28 \mathrm{c}$ and $\mathrm{d}$, yielded very similar spectra, in which the $g$-value for prominent lines was 2.0034. The most prominent parts of these spectra also somewhat resemble the spectrum of maltose, figure $28 \mathrm{e}$. These three latter spectra therefore seem to exhibit common features of units connected by $\alpha-1,4$ linkages, although the details are not readily deciphered. Amylose suspensions, prepared either directly or by neutralization of the hot alkaline solution and rapid cooling (10 to $15 \mathrm{~min}$ ) were not sufficiently swollen to yield any spectrum other than hydroxyl. A number of simple carbohydrate spectra are described in the literature [29b].

\section{Conclusion}

The attack of hydroxyl radicals upon water-soluble polymers in acid solution generates radicals with narrow-line hyperfine structure. As with smaller molecules of related structure, abstraction is the dominant mode of attack. Exceptions may occur in polymeric carbohydrates and polyhydroxy compounds, where a case has been made for abstraction followed by $\beta$ hydroxyl loss. The preferred site is usually at an oxygen-bearing functional group; exceptions are the carboxylic acids and polyvinyl alcohol. Subsequent reactions of the initially formed radicals were seldom detected in the short time-scale of the experiments; however, in the case of polyethylene oxide the proportion of radicals which might be associated with chain scission, perhaps $m \mathrm{CH}_{2} \dot{\mathrm{C}} \mathrm{HOH}$, increased with time and at high temperature. The observed radicals may be important intermediates in radiolytic changes of such materials as dextran and methylcellulose in aqueous solution. Polymers which form gel in aqueous radiolysis also tended to form gel when attacked by hydroxyl generated from titanous ion and hydrogen peroxide.

\section{References}

[1] W. T. Dixon and R. O. C. Norman, Nature 196, 891 (1962).

[2] W. T. Dixon and R. O. C. Norman, J. Chem. Soc. 3119 (1963).

[3] W. T. Dixon, R. O. C. Norman, and A. L. Buley, J. Chem. Soc. 3625 (1964).

[4] W. T. Dixon and R. O. C. Norman, J. Chem. Soc. 4850 (1964).

[5] W. T. Dixon and R. O. C. Norman, J. Chem. Soc. 4857 (1964).

[6] A. L. Buley and R. O. C. Norman, Proc. Chem. Soc. 225 (1964).

[7] J. T. Pearson, P. Smith, and T. C. Smith, Can. J. Chem. 42, $2022(1964)$.

[8] H. Fischer, Z. Naturforsch 19a, 866 (1964).

[9] R. Livingston and H. Zeldes, J. Chem. Phys. 44, 1245 (1966).

[10] J. H. Flynn, L. A. Wall, and W. L. Morrow, J. Res. NBS 71 A (Phys. and Chem.) No. 1, 25 (1967).

[11] F. Sicilio, R. E. Florin, and L. A. Wall, J. Phys. Chem 70, 47 (1966).

[12] J. S. Hyde, private communication.

[13] J. Q. Adams, S. W. Nicksic, and J. R. Thomas, J. Chem. Phys. 45, 654 (1966).

[14] Y. Sakurada, M. Matsumoto, K. Imai, A. Nishioka, and Y. Kato, J. Polymer Sci. 1B, 633 (1963), and references therein.

[15a] Y. S. Chiang, J. Craddock, D. Michewich, and J. Turkevich, J. Phys. Chem. 70, 3509 (1966).

[15b] F. Sicilio, M. Dousset, R. E. Florin, and L. A. Wall, presented at 150th Am. Chem. Soc. Meeting, Polymer Preprints 6, 958 (1965).

[15c] D. Kivelson, J. Chem. Phys. 33, 1094 (1960).

[15d] J. H. Freed and G. K. Fraenkel, J. Chem. Phys. 41, 699 (1964).

[15e] J. W. H. Schreurs and G. R. Fraenkel, J. Chem. Phys. 34, 756 (1961).

[15f] A. D. McLachlan, Mol. Phys. 1, 233 (1958).

[15g] A. Horsfield, J. R. Morton, and D. H. Whiffen, Mol. Phys. 4, 425 (1961).

[15h] J. H. Freed and G. K. Fraenkel, J. Chem. Phys. 39, 326 (1963).

[16] R. W. Fessenden, J. Chem. Phys. 37, 747 (1962).

[17] R. W. Fessenden and R. H. Schuler, J. Chem. Phys. 39, 2147 (1963).

[18] C. J. W. Gutch and W. A. Waters, J. Chem. Soc. 1965, 751 (1965).

[19] R. E. Florin, F. Sicilio, and L. A. Wall, unpublished.

[20] T. Cole, J. Chem. Phys. 35, 1169 (1961).

[21] J. S. Hyde and E. S. Freeman, J. Phys. Chem. 65, 1636 (1961).

[22] W. R. Dunstan and E. Goulding, J. Chem. Soc. 75, 1004 (1899).

[23] J. H. Merz and W. A. Waters, J. Chem. Soc. 1949, S15 (1949).

[24] R. P. Kohin and P. G. Nadeau, J. Chem. Phys. 44, 691 (1966).

[25] R. C. DuVarney and R. P. Kohin, J. Chem. Phys. 44, 2532 (1966).

[26] H. Normant, Chimie Ind. 63, [3 bis], 509-10 (1950); C. A. 47, 6393b (1953).

[27] H. Zeldes and R. Livingston, private communication; H. Zeldes and R. Livingston, J. Chem. Phys. 45, 1946 (1966).

[28] A. L. Buley, R. O. C. Norman, and R. J. Pritchett, J. Chem. Soc. (B), 849 (1966).

[29] N. M. Bazhin, E. V. Kuznetsov, N. N. Bubnov, and V. V. Voevodskii, Kinetika i. Kataliz 7, 732 (1966)

[29a] P. J. Baugh, O. Hinojosa, and J. C. Arthur, Jr., J. Phys. Chem. 71, 1135 (1967).

[30] F. K. Beilstein, Beilsteins Handbuch der Organischen Chemie EIII, Vol. 1, Part 2 (Springer-Verlag, Berlin, 1958) p. 2308.

[31] L. F. Fieser and M. Fieser, Advanced Organic Chemistry, p. 969 (Reinhold, New York, 1961).

[32] M. C. R. Symons, Tetrahedron 18, 333 (1962).

(Paper 72Al-481) 